\title{
PERCEPCIÓN ACERCA DE LA CIENCIA Y LA TECNOLOGÍA EN ESTUDIANTES Y DOCENTES DE LA UNIVERSIDAD DE CALDAS
}

\author{
LORENA GARTNER ISAZA ${ }^{1}$
}

Manizales, 2010-03-01 (Rev. 2010-05-20).

\section{RESUMEN}

La percepción sobre ciencia y tecnología hace referencia a la imagen con la que se les asocia y a aquellas nociones y expectativas que contienen alguna carga valorativa de cada una de estas dos entidades. En el presente artículo se abordan los siguientes aspectos: la idea que docentes y estudiantes de la Universidad de Caldas tienen acerca de ellas; la valoración con respecto a algunos ámbitos de aplicación específicos; el balance global que de ellas se hace; la idea acerca de los campos en los cuales se cree que se enfoca prioritariamente el desarrollo tecnocientífico; las creencias sobre el manejo de la ciencia en el mundo; el punto de vista acerca de la accesibilidad de la ciencia y la tecnología al público; y la imagen de la profesión de investigador en el ámbito local.

Las respuestas de los docentes y los estudiantes de la Universidad de Caldas sobre estos aspectos se relacionan con otras variables, tales como: el nivel educativo, la procedencia, el autoposicionamiento político y religioso, el nivel socioeconómico, el género, la edad y el campo del conocimiento. Así mismo, se efectúa una comparación con los resultados de las más recientes encuestas iberoamericanas de percepción social acerca de la ciencia y la tecnología en las que se encuentra información cotejable.

\section{PALABRAS CLAVE:}

Ciencia, tecnología, tecnociencias, percepción social.

\section{PERCEPTION ON SCIENCE AND TECHNOLOGY IN STUDENTS AND PROFESSORS FROM THE UNIVERSIDAD DE CALDAS}

\begin{abstract}
The perception on science and technology refers to the image with which they are associated and to the notions and expectations containing any evaluative load regarding either one of these entities. The present article deals with the following aspects: the idea students and professors from the Universidad de Caldas have on those concepts; the assessment related to some specific application fields; the global balance regarding science and technology; the idea on the fields in which the techno-scientific development is believed to primarily focus on; the beliefs on science management in the world; the point of view regarding the accessibility of science and technology to the public; and the image of the researcher at a local level. The answers of professors and students from the Universidad de Caldas about these aspects are related to other variables, such as educational level, origin, political and religious self-positioning, socio-economic level, genre, age and field of knowledge. In the same manner, a comparison with the results of the most recent Latin American surveys on social perception on science and technology is carried out in which comparable information can be found.
\end{abstract}


KEY WORDS: science, technology, techno-sciences, social perception.

\section{INTRODUCCIÓN}

La ciencia y sus aplicaciones tecnológicas constituyen variables de enorme relevancia para la comprensión de las dinámicas sociales, económicas y culturales contemporáneas, por consiguiente, las investigaciones sociales acerca de la ciencia y la tecnología constituyen un campo de trabajo en Humanidades y en Ciencias Sociales con un creciente desarrollo a nivel internacional. En el marco de los estudios sociales de la ciencia y la tecnología han emergido varias líneas de trabajo, entre las que se encuentra la relacionada con la percepción pública acerca de la ciencia y la tecnología, que se refiere a la imagen con ellas asociada y a las nociones y expectativas que contienen alguna carga valorativa de cada una de estas dos entidades. De los resultados de tales indagaciones se han ido aportando criterios para la definición de políticas públicas y herramientas de gestión al respecto; constituyen, por tanto, insumos de particular utilidad para el fomento de la cultura científica y de la implicación social. En consecuencia, no sólo es importante conocer la percepción social que se tiene sobre la ciencia y la tecnología en los contextos nacionales, como de suyo se ha hecho en muchos países, sino también saber qué imagen se tiene de ellas en los contextos locales. En este sentido, el presente artículo hace referencia a algunos de los resultados arrojados por el estudio acerca de la percepción social que sobre ciencia y tecnología se posee en un ámbito académico local, la Universidad de Caldas, el cual exhibe sintonía con una necesidad reconocida a nivel internacional y nacional, y posee un carácter novedoso, ya que precisa un tema muy poco estudiado en ámbitos institucionales educativos que por su naturaleza están relacionados con la actividad científica y tecnológica, tal es el caso de las instituciones de Educación Superior, para las cuales puede constituirse en un referente para el desarrollo de sus políticas investigativas y para sus estrategias de formación de investigadores. En este contexto, podría decirse que la comunidad académica universitaria (docentes y estudiantes) constituye un grupo social que, de modo privilegiado, se encuentra más cercano a las actividades de producción y de difusión de la ciencia y la tecnología, lo que la convierte en una población con mayor cualificación en el conjunto de la sociedad para sus apreciaciones al respecto.

Este estudio fue desarrollado por el equipo de trabajo del Semillero de Investigación sobre Estudios Sociales de la Ciencia y la Innovación Tecnológica en el que participaron las estudiantes: Adriana Isabel Muelas, Diana Carolina Londoño, Yuliana Gutiérrez y Valentina Vásquez. Con miras a obtener una mayor comprensión de las variables estudiadas concernientes con la percepción acerca de la ciencia y la tecnología en docentes y estudiantes de la Universidad de Caldas, éstas se relacionaron con otras referidas a algunas características sociodemográficas de esta población, tales como edad, género, área de formación, estrato socio-económico, procedencia, autoposicionamiento religioso y político. Así mismo, en la medida de la disponibilidad de datos cotejables de las más recientes encuestas iberoamericanas sobre la percepción social acerca de la ciencia y la tecnología, se avanza en la comparación con los resultados locales de la población estudiada. 


\section{METODOLOGÍA}

Con miras a garantizar la comparabilidad, este estudio se diseñó de manera tal que guardara correspondencia temática y metodológica con las diferentes encuestas nacionales realizadas sobre percepción de la ciencia y la tecnología en países iberoamericanos como España, Argentina, Uruguay, Brasil, Portugal, México, Panamá, Venezuela, Colombia, Ecuador y Trinidad y Tobago. Tomando este referente se efectúo una selección y adaptación de indicadores. Cabe señalar que desde el año 2001 la Red de Indicadores de Ciencia y Tecnología (RICYT), la Organización de Estados Iberoamericanos (OEI) y la Fundación Española de Ciencia y Tecnología (FECYT) han venido trabajando en el Proyecto Iberoamericano de Indicadores de Percepción Pública, Cultura Científica y Participación Ciudadana, con el propósito de avanzar en la construcción de metodologías e indicadores que, a partir de la tradición internacional, fuesen pertinentes para el contexto de la ciencia, la tecnología y la cultura iberoamericanas.

Ámbito: Universidad de Caldas, institución pública de Educación Superior localizada en el municipio de Manizales, departamento de Caldas, Colombia.

Universo: total de estudiantes matriculados en los programas de pregrado en la Universidad de Caldas en 2008 (9126 en total), y total de docentes vinculados en este período, mediante cualquier tipo de contratación (planta, ocasional, cátedra) (834 en total).

Muestra: aleatoria y estratificada por facultades: Ciencias Agropecuarias, Ciencias Jurídicas y Sociales, Artes y Humanidades, Ciencias para la Salud e Ingenierías. Para estudiantes un margen de error del $5 \%$ y un nivel confianza del $95 \%$ (381 en total), y para los docentes un margen de error del $7 \%$ y un nivel confianza del $95 \%$ (97 en total).

Siguiendo la tradición de las encuestas de percepción sobre ciencia y tecnología, este estudio adquiere un carácter demoscópico (sondeo y medición estadística tomada a partir de encuestas destinadas a conocer la opinión pública). El proceso empírico o acercamiento al objeto de conocimiento se efectuó mediante entrevista estructurada (encuesta) con preguntas cerradas dicotómicas, de opción múltiple y escalas de intensidad. Esta encuesta fue validada a través de prueba piloto y diligenciada en forma personal, en el segundo período académico de 2009.

\section{DISCUSIÓN Y RESULTADOS}

\section{Algunos referentes}

A lo largo del siglo $X X$, especialmente en su segunda mitad, se produjo una revolución científica y tecnológica que ha conducido a un profundo cambio social y económico. Tal revolución también expresada en la contracción tecnociencia hace referencia a la creciente interdependencia entre las actividades científicas y tecnológicas, sin que con ello se quiera significar la desaparición de las especificidades de estas dos actividades. Desde el punto de vista axiológico, en esta hibridación ambas mantienen sus respectivas orientaciones valorativas, tanto científicas (epistémicas) como técnicas. Javier Echeverría (2003) se refiere a sus rasgos distintivos de la siguiente manera: 
Por ser tecnología, la tecnociencia no sólo busca conocimiento verdadero (o verosímil, o contrastable, o falsable), sino también conocimiento útil. Pero por ser ciencia, tampoco basta con que las acciones tecnocientíficas sean útiles o eficaces, sino que además se requiere que estén científicamente justificadas [...] La verdad, la verosimilitud, la generalidad, la adecuación empírica, la precisión y la coherencia siguen siendo valores relevantes para la tecnociencia, pero los valores epistémicos no son los únicos. La tecnociencia incorpora a su núcleo axiológico buena parte de los valores técnicos (utilidad, eficiencia, eficacia, funcionalidad, aplicabilidad, etc.) y aunque sigue manteniendo los valores epistémicos, el segundo subsistema de valores tiene un peso tan considerable como el primero. (p. 67)

Ahora bien, en las condiciones socio-económicas, culturales y políticas contemporáneas, en todo el orbe, las tecnociencias ocupan un lugar estratégico como factor de desarrollo ${ }^{2}$ entendido este último no sólo como crecimiento económico, sino también $\mathrm{y}$, esencialmente, como mejoramiento de las condiciones de vida humana y preservación de la diversidad biótica y cultural. Con esto no se quiere sugerir que las ciencias y las tecnologías constituyan los únicos factores ligados con propósitos de bienestar social y de desarrollo humano, los cuales, de suyo, incorporan una gran variedad de componentes que les otorgan naturalezas bien complejas. Sin embargo, a pesar de la intrincada fisonomía del desarrollo humano y social, sin duda, las ciencias y las tecnologías tienen enormes potencialidades para la solución de problemas sociales, políticos, culturales, económicos y ambientales; éstas son insoslayables para un desarrollo sustentable, dado que, en la actualidad, las ventajas competitivas de los países ya no se basan prioritariamente en su ubicación geográfica y en la tenencia de recursos naturales, sino en la capacidad de aprovechamiento de estos recursos, mediante la incorporación de valor agregado como consecuencia de la generación y aplicación de conocimientos e información. De este modo, la construcción de futuro para la humanidad se cimienta, en buena medida, en el conocimiento, cuyo crecimiento es exponencial y cada día más especializado, interdependiente

$\mathrm{y}$ globalizado.

Al reconocer el protagonismo de las tecnociencias como factor de desarrollo, no se está soslayando la reflexión acerca de sus secuelas negativas, pues las nuevas fronteras conquistadas en el campo del conocimiento y sus aplicaciones permiten ver a las ciencias y a las tecnologías no sólo como promesas de calidad de vida, sino también, como factores de incertidumbre y de riesgo, pues no son subestimables sus demostrados impactos negativos y su potencial letal en muchas de sus aplicaciones. Cabe decir que la enorme capacidad humana para crear, transformar y desentrañar los secretos de la naturaleza y de la sociedad coexiste con su también enorme capacidad destructiva. La ciencia y la tecnología han sido puestas en uno y otro lado, sin embargo, hoy, éstas son inevitables y necesarias. En la actualidad, la masiva reorganización productiva y comercial con alcance global, en el marco de una feroz competencia económica, escenifica crisis no menos que dramáticas en los campos social y ambiental, lo que le genera una tesitura especialmente compleja y crítica a la relación cienciatecnología-sociedad. Las tecnociencias se hallan bajo el fuego cruzado de diversos actores estatales, privados y sociedad civil organizada que le exigen resultados de disímil naturaleza, en tanto se constituyen en bienes económicos, políticos y militares. Como lo expresa Javier Echeverría (2003): "el conocimiento tecnocientífico ha dejado de ser un bien en sí para ser un bien desde unos puntos de vista y un mal desde otros" (p. 106), "los fines de la ciencia y la tecnología dejan de ser valores últimos para convertirse en valores instrumentales" (p. 37). 
En tanto, cada día con mayor intensidad, las ciencias han desbordado los ámbitos en los que se producen y sus aplicaciones hacen presencia en todos los espacios de la vida humana, sin riesgo a equívocos, es posible afirmar que devienen en variable particularmente relevante para la explicación de las grandes y vertiginosas transformaciones de la sociedad que nos es contemporánea, en tanto "impactan en las dimensiones sociales variadas: la economía; la política; la comunidad (en términos de la sociedad civil); los dominios institucionales especializados (salud, educación, ley, bienestar y seguridad social, etc.); la cultura y los valores -industria cultural, creencias, normas y comportamientos-" (Albornoz, 2003, p. 4). Las tecnociencias no son asunto que interese sólo a los científicos y a los tecnólogos; ellas se han hecho ciudadanas, como lo afirman Lafuente y Saraiva (2002): "se han mundanizado", pues están presentes en las decisiones del día a día de las personas en particular, de los gobernantes, de los empresarios y, por supuesto, de los científicos; decisiones que van desde la adquisición de un producto en el mercado, la inversión o no en determinados campos del conocimiento, la modificación genética, la seguridad alimentaria, los medios de transporte, la conservación del ambiente, etc., a manera de ejemplo. Por consiguiente, en la medida en que la ciencia compromete la vida de los ciudadanos, se hace urgente el diálogo entre ésta y la sociedad en todos sus niveles: administradores públicos, tecnólogos, empresarios, organizaciones sociales y ciudadanos, pues los sistemas tecnocientíficos poseen una enorme complejidad en la que existe una tensa relación entre sus diversos agentes ${ }^{3}$, quienes poseen una gran cantidad de intereses, por lo que su estructura es esencialmente conflictiva.

Aunque existe consenso en torno al papel del conocimiento en el desarrollo económico y social, también es ampliamente reconocido que éste en sí mismo no transforma a las sociedades. En tal sentido, el volumen de conocimientos generados por una sociedad no garantiza su incorporación a procesos dirigidos al mejoramiento de las condiciones de vida humana y la calidad de su entorno, se requiere de su acertada aplicación y su correcta administración. La producción científica no culmina necesariamente en decisiones, productos o procesos en el ámbito privado o en las políticas públicas, para tal efecto, se requieren reales voluntades que movilicen actores y recursos orientados al desarrollo científico y tecnológico con miras al bienestar de las sociedades. Es así como se han ido desarrollando y consolidando, a nivel planetario, sistemas nacionales de ciencia, tecnología e innovación que, separados del modelo lineal, también llamado de ósmosis, que concebía el transito natural del 'laboratorio a la empresa' (expresado en la ecuación: + ciencia $=+$ tecnología $=+$ desarrollo productivo $=+$ competitividad económica $=+$ progreso social), intentan incentivar la práctica de la investigación científica para la utilización del saber derivado de ella en la solución de problemas sociales y ambientales y en los sectores de producción de bienes y servicios. En tal sentido, la dinámica de la investigación científica presenta un fortalecimiento del llamado 'Modo 2' o 'modo de aplicación', cuyo propósito es aportar a algún sector del gobierno, de la industria o de la sociedad $\mathrm{civi}^{4}$; este modo de producción de conocimiento obliga a la puesta en escena de actores de diverso tipo que hagan posible una verdadera dinámica interactiva como condición de posibilidad para el desarrollo de un sistema de conocimientos socialmente distribuido. Es así como el tradicional 'Modo 1' de producción de conocimiento o modalidad de ciencia académica fuertemente disciplinaria, tiende a erosionarse y a perder protagonismo en la agenda de las políticas de ciencia y tecnología en todo el orbe.

Al respecto, no se trata de establecer algún tipo de determinismo, dígase el determinismo científico y tecnológico que considera a la sociedad condicionada por los desarrollos tecnocientíficos o el determinismo social que considera los componentes sociales, económicos y políticos como agentes causales de la ruta 
científica y tecnológica. La relación ciencia.tecnología-sociedad no es unidireccional; entre ellas, se sucede un dinámico flujo de interacciones en varias direcciones que compromete no solamente los sistemas tecnocientíficos, sino también los sistemas sociales en sus aspectos de tipo cultural, político y económico. Las concepciones que le otorgan autonomía a uno u otro sistema abordan la cuestión de una manera parcial; ambos sistemas establecen reciprocas relaciones de causa y efecto. Las capacidades de una sociedad para producir conocimientos, apropiarlos, usarlos y distribuirlos están condicionadas por una compleja red de procesos y actores que evoca la idea de sistema de conocimiento que se configura, entre otros, de acuerdo con:

a. la forma como cada sociedad en sus diferentes sectores empresariales y de gestión pública demanda desarrollos científicos;

b. los sistemas educativos y su participación en la formación de gestores de conocimientos capaces de aportar al desarrollo de la sociedad;

c. las políticas y los recursos para el fomento de la actividad científica y su retorno social;

d. la capacidad de las instituciones sociales y de las empresas para absorber conocimientos;

e. las interacciones entre las instituciones para el desarrollo científico y de las comunidades académicas con la sociedad civil, con las instituciones privadas y con el Estado; y

f. los medios de comunicación y su relación con las comunidades académicas.

Los encuentros entre la ciencia y el público poseen significativa importancia tanto en las decisiones de política científica y de políticas públicas en general, como en las intervenciones empresariales y en las prácticas cotidianas. La participación ciudadana en los asuntos concernientes con las ciencias y sus aplicaciones tecnológicas es ahora una exigencia de la democracia y en tal sentido, las tecnociencias deben ser valoradas, entre otros, en el contexto de los proyectos sociales en los que se insertan, los intereses que atienden y los actores que le otorgan sentido. De este modo, las dinámicas de interacción entre la ciencia, la tecnología y la sociedad abren un denso campo investigativo y de reflexión para las ciencias sociales, donde la percepción pública, la cultura científica y la participación ciudadana emergen como categorías de particular interés.

La euforia frente a la tecnociencia tiene sus orígenes en idea baiconiana de progreso de la civilización catapultado por el conocimiento científico y en el desarrollo del positivismo decimonónico, encabezado, entre otros, por SaintSimon y A. Comte, donde las nociones de progreso y desarrollo de la humanidad han sido ligadas a la superación de los estadios teológico y metafísico, y al predominio de la razón y de la técnica (estadio científico o positivo, referente fundamental de la emergente sociedad industrial). Estas ideas tecnofílicas tuvieron una presencia dominante en la atmósfera política, social y cultural de las sociedades occidentales, en tanto el bienestar y el progreso se percibían necesariamente asociados al desarrollo científico y tecnológico. La actividad científica y tecnológica norteamericana y de muchos estados de la Europa Occidental de la primera mitad del siglo pasado sirvió para entender que ésta no solamente era útil para la defensa nacional, sino también para propósitos 
políticos (Capitalismo vs. Comunismo), y para la competencia económica internacional.

En las primeras décadas de la segunda mitad del siglo pasado, se consolidaron movimientos sociales reactivos al desarrollo tecnocientífico (ambientalistas, feministas, pacifistas) motivados principalmente por sus aplicaciones en la industria bélica (confrontaciones mundiales, Vietnam, Corea, etc.) y sus devastadores efectos en el ambiente. La izquierda intelectual, nutrida por autores como Chomsky, Habermas, Marcuse o Feyerabend en su crítica al cientifismo y a la tecnocracia, tuvo gran influencia en esta reacción tecnófoba, al igual que muchas de las posturas románticas de derecha como la de Martin Heidegger. En esta dinámica social contestataria también participaron científicos y tecnólogos:

ya durante los años cuarenta, y fruto de su difícil relación profesional con las instituciones militares, grupos de científicos críticos constituyeron en el Reino Unido y Estados Unidos la Association of Scientific Workers. Hacia finales de los sesenta y durante la década de los setenta, otros colectivos como la British Society for Social Responsibility in Science, Scientists and Engineers for Social and Political Action (posteriormente, Science for the People) o los Public Interest Research Groups desplegaron, igualmente, una gran actividad de índole contestataria. (Moreno \& Lujan, 1996, p. 131)

Tras la finalización de la Segunda Guerra Mundial, que supuso un hito en el apoyo social a la ciencia y la tecnología, comenzaron a constatarse a lo largo de la década de los cincuenta y sesenta del siglo pasado una serie de hechos que afectaron a la confianza otorgada a la tecnociencia. En efecto, la carrera armamentística nuclear que desencadenó la Guerra Fría, asociada con el recuerdo de muerte y destrucción de Hiroshima y Nagasaki, la creciente constatación de los riesgos potenciales y peligros reales de los residuos tóxicos químicos y nucleares, las distintas manifestaciones del visible y continuo deterioro del medio ambiente, la posibilidad real de alterar los ciclos básicos de la naturaleza, la aceleración del proceso de disolución de los saberes y experiencias tradicionales, la creciente deshumanización y alienación en los puestos de trabajo por razón de la tecnificación de la cadena productiva y, en suma, la asunción de unas pautas de producción y consumo que cambiaron los valores morales por las necesidades y los estilos de vida naturales por sofisticadas formas artificiales, supusieron el definitivo espaldarazo para que, a partir del momento simbólico del Mayo del 68, comenzara a producirse una progresiva erosión en la confianza de la sociedad en la tecnociencia, y la consiguiente activación de las posiciones críticas. (FECYT, 2007, p. 198)

A partir de los años 70 se empezó a consolidar un nuevo contexto en el que se hacía necesario potenciar nuevos mercados y abrir nuevos sectores productivos intensivos en el uso del conocimiento, y en el que se evidencia que el crecimiento económico no es condición suficiente para el progreso social. Allí, esta criatura de la modernidad, la tecnociencia, llámese Prometeo o Frankenstein, se cierne sobre la sociedad como factor tanto de riesgo como de bienestar, y se deposita en la médula de muy buena parte de sus procesos comprometiendo la trama de la existencia individual y colectiva con impactos diferenciados.

La suerte esta echada y el vertiginoso avance de la ciencia y la tecnología, en el marco de la sociedad industrial de tipo capitalista, alienta a que muchos de los estados del planeta empiecen a generar condiciones estructurales para el desarrollo y consolidación de sistemas nacionales de ciencia y tecnología, en primera instancia en los países más desarrollados. De forma paralela a este proceso, en buena parte como consecuencia de la antedicha reacción crítica, la 
comunicación de la ciencia con la sociedad también comienza a ocupar un lugar en las políticas públicas de ciencia y tecnología. La demanda ciudadana por el establecimiento de límites al tradicional modelo crecimiento económico que aboga por la mejora de la calidad de vida, los movimientos sociales en pro del desarrollo de tecnologías apropiadas acordes con las expectativas y valores sociales, la evaluación del riesgo, el gradual incremento de sectores que pretenden influir en el curso tecnocientífico de las sociedades (investigadores, tecnólogos, economistas, administradores, grupos de presión, empresarios) dibujan el escenario en el que, a partir de los años 70 , se desarrolló un creciente interés por la percepción y las actitudes públicas hacia la ciencia y la tecnología hasta lograr posicionarse en las agendas para el diseño de estrategias y políticas públicas en muchos países. Ante la necesidad de conocer las percepciones públicas frente a la ciencia y la tecnología, desde entonces y de manera progresiva, se movilizan acciones tendientes a definir indicadores y formas de medida, por supuesto, cimentadas en concepciones e intereses diversos.

En este ambiente, el público empieza a desempeñar un importante rol como futuro usuario de las innovaciones tecnocientíficas, cuya implantación está mediada por la aceptación social. Para tal efecto, se hace necesario esclarecer algunas claves de intervención en función de las diferentes actitudes (o disposiciones para la acción) y de los significados e intereses de distintos grupos sociales. En tal sentido, los estudios de percepción pública aportan a la identificación de escenarios tecnocientíficos y de políticas públicas necesarias para conducir desarrollos considerados como beneficiosos socialmente y para gestionar, regular y evitar el riesgo.

Pionera en el desarrollo de estas indagaciones ha sido la agencia norteamericana National Science Foundation (NSF), cuyos análisis, desde 1972, se han extendido a escala internacional, en tanto realiza seguimiento, diferencia en subpoblaciones las actitudes y la comprensión pública de la ciencia en Estados Unidos y efectúa comparaciones con estudios análogos realizados Japón y en Europa. Los protocolos desarrollados por la NSF, así como han sido blanco de acaloradas controversias, han sido objeto de atención institucional e influencia política en muchos países y se han constituido en la referencia clásica para este tipo de estudios, pues sus volúmenes anuales sobre Indicadores de Ciencia e Ingeniería incorporan un capítulo dedicado a la comprensión y actitudes del público respecto del desarrollo científico-tecnológico. Desde 1988 se conoce la encuesta del Reino Unido y el Proyecto de la Comisión Europea, nombrado como Eurobarómetro y, sucesivamente, se han ido desarrollando otros esfuerzos, por ejemplo, en India, Corea del Sur, China, Malasia, Nueva Zelanda, Japón y Rusia. En Iberoamérica, a partir del año 2001, se ha realizado una serie de encuestas para el análisis de las diferentes percepciones públicas sobre la ciencia y la tecnología lideradas por Organización de los Estados Iberoamericanos (OEI), la Red Iberoamericana de Ciencia y Tecnología (RICYT) y la Fundación Española para la Ciencia y la Tecnología (FECYT), en el marco del Proyecto Estándar Iberoamericano de Indicadores de Percepción Pública, Cultura Científica y Participación Ciudadana ${ }^{5}$. Hasta el momento se ha realizado este tipo de estudios en: España, Argentina, Chile, Uruguay, Brasil, Portugal, México, Panamá, Venezuela, Colombia, Ecuador y Trinidad y Tobago.

Este interés por acercar la ciencia a sus públicos a partir del conocimiento de sus percepciones se ha desarrollado desde diversos enfoques, pero siempre con la intención de hacer de ellos herramientas de gestión para las políticas públicas de ciencia y tecnología en las que se introduce la perspectiva ciudadana. Cabe reseñar las dos grandes tradiciones que han marcado este proceso: la tradición norteamericana, conocida como scientific literacy, orientada a identificar el grado de alfabetización científica de la sociedad, cuya resultante es la verificación de 
saberes certificados como verdaderos; y la tradición británica, conocida como public understanding of science, enfocada hacia la identificación de actitudes frente a la ciencia y la tecnología. Los modelos desarrollados por estas dos tradiciones han sido la base de políticas y acciones de instituciones que han movilizado actores sociales diversos en torno a museos, asociaciones científicas, medios masivos de comunicación, periodistas científicos, instituciones educativas, entre otros.

El precursor en este tipo de estudios correspondió a una lógica "deficitaria", en el marco de la indicada tradición norteamericana scientific literacy, según la cual, se espera identificar qué tanto conocimiento público existe sobre la ciencia (conocimiento de conceptos, leyes, teorías, etc.) y, de esta manera, reconocer la dimensión del comportamiento anti-científico que debería ser corregido mediante programas de alfabetización científica en un esquema lineal que buscaba legitimar la labor de la comunidad científica y tecnológica. Este tipo de aproximación a la 'cultura científica' es restringida y correspondiente con el modelo de 'erudición', basado en la definición enciclopédica de cultura. Desde esta perspectiva, coinciden muchos autores en señalar que las diferencias de conocimiento entre los científicos y el público se interpretan en términos de ignorancia que los resultados de los estudios no hacen más que resaltarla, pues lo que se evidencia, obviamente, son las insuficiencias del público frente a los conocimientos que posee la comunidad científica; por esta vía argumental se asume que a mayor conocimiento, en este caso información sobre asuntos tecnocientíficos, mayor apoyo y legitimación de éstos.

Las críticas suscitadas a este enfoque han llevado a que se incorporen aspectos actitudinales y valorativos con la perspectiva de adelantar acciones orientadas a promover aprecio hacia la ciencia (public understanding of science), de tal manera que:

las encuestas ya no se orientan tanto a determinar cuánto sabe la gente sobre ciencia sino cuánto valora la ciencia. Aparecen así una serie de preguntas asociadas al estatus que le otorgan las personas a la ciencia frente a otras áreas de la cultura, sus representaciones sobre los científicos y su percepción de los posibles riesgos que la ciencia pueda entrañar. De estas preguntas se desprende la conclusión de que lo que hay que hacer, ya no es educar al público sino seducirlo, haciendo gran énfasis en el papel de los mediadores como los museos, el periodismo científico y medios de comunicación, las ferias y eventos de ciencia, de los cuales se esperan ejercicios de traducción efectivos donde la ciencia sea mostrada como una práctica social, logrando en los públicos la valoración de sus prácticas e implicaciones sociales y de esta forma la toma de decisiones informada. (Daza, 2008, p. 5)

Este proceso de refinamiento de los criterios e instrumentos para acceder a la percepción pública en sociedades particulares, aunque no exento de polémica, ha ido abriendo el foco de observación e interés y tiende a orientarse hacia el amplio espectro de la cultura científica, como se advierte en el ya mencionado Proyecto Iberoamericano de Indicadores de Percepción Pública, Cultura Científica y Participación Ciudadana. En el marco de este proyecto, se abandona el concepto de cultura científica como atributo individual que evoca el cúmulo de saberes apropiados por sujetos en particular (forma de instrucción o acumulación de saber) y se asume como atributo fundamentalmente social, constituido por el complejo conjunto de elementos que hacen parte de la organización social de la cultura y que interactúan dinámicamente con ésta y se expresa en contenidos cognitivos, simbólicos, institucionales, normativos y organizacionales relacionados con la producción y uso científico y tecnológico. Así: 
La "cultura científica" en sentido amplio, entonces, tendría como objeto la indagación de diferentes aspectos de la dinámica social de la actividad científica, entre ellos: a) nivel de aplicación de las prácticas científicas y tecnológicas en actividades (instituciones) seleccionadas relevantes (definición de políticas, consumo individual, etc.); b) información relevante a nivel público acerca de cuestiones referidas a la ciencia y la tecnología; c) grado de desarrollo de la cultura CTS: identificación de intereses, visión crítica del riesgo, capacidad democrática de orientación de la ciencia, la tecnología y la innovación; d) asignación de recursos a la actividad científica; e) participación ciudadana en controversias derivadas de la ciencia y la tecnología; f) nivel de conocimiento o comprensión del público; g) actitudes hacia la ciencia y la tecnología: credibilidad de la ciencia y de la actividad científico-tecnológica; h) evaluación del riesgo; o i) reproducción del sistema de ciencia y tecnología: dinámica de incorporación de nuevos investigadores, pirámides poblacionales de agentes de ciencia y tecnología, tasas de emigración y de retorno de científicos, entre otros. (Vaccarezza, López, Lujan, Fazio \& Polino, 2003, p. 33)

Ahora bien, cabe asociar esta connotación del concepto de cultura científica en sentido amplio, adoptado en el Proyecto referido, con en el concepto de cultura técnica desarrollado por Miguel Ángel Quintanilla. Este filósofo español utiliza la propuesta de Jesús Mosterín en el sentido en que la cultura de un grupo social está formada por el conjunto de representaciones, creencias, reglas y pautas de comportamiento, sistemas de preferencias y valores en función de determinados contenidos culturales (políticos, religiosos, científicos, etc.). La cultura, según Mosterín, se refiere a información transmitida por aprendizaje social y "puede ser de tres tipos: representacional (información acerca de las características y propiedades del medio), práctica (información acerca de cómo hay que actuar) y valorativa (información acerca de qué estado de cosas son preferibles, convenientes o valiosos)" (Quintanilla, 2001, p. 63). Así el profesor Quintanilla desarrolla los aspectos principales de la cultura técnica y que bien podría permitirse la licencia de nombrarla en el presente trabajo como cultura tecnocientífica.

- Los conocimientos, creencias y representaciones conceptuales o simbólicas sobre las técnicas [tecnociencias] y sobre los sistemas técnicos [tecnocientíficos]. Llamaremos a esto el contenido simbólico o representacional de la cultura técnica [tecnocientífica].

- Las reglas y pautas de comportamiento, habilidades y conocimientos operacionales referidos a sistemas técnicos [tecnocientíficos]. Llamaremos a esto el componente práctico de la cultura técnica [tecnocientífica].

- Los objetivos, valores y preferencias relativos al diseño, adquisición, uso, etc., de los sistemas técnicos [tecnocientíficos] y de conocimientos técnicos [tecnocientíficos]. Llamaremos a esto el componente valorativo o axiológico de la cultura técnica [tecnocientífica]. (Ibíd., p. 64)

Particularmente, en el marco de los esfuerzos de estandarización, con miras a garantizar comparabilidad entre países, desarrollado a través del Proyecto Iberoamericano de Indicadores de Percepción Pública, Cultura Científica y Participación Ciudadana, se ha trabajado en la construcción de indicadores y metodologías que, "tomando en cuenta la tradición internacional, estuvieran situados regionalmente y, por lo tanto, fueran pertinentes para el contexto de la ciencia, la tecnología y la cultura iberoamericanas" (FECYT, OEI, et al, 2009, p. 11). En dicho proceso, "se han incorporado componentes simbólicos y cognitivos expresados en actitudes, valoraciones y conocimientos (fácticos e institucionales), con el propósito de identificar expectativas sociales sobre el desarrollo científico-tecnológico y sus impactos económicos, sociales y 
culturales" (Ibíd., p. 11), con el fin de encausar acciones orientadas hacia el desarrollo de la cultura científica o cientifización de la cultura, entendida como "la medida en que la ciencia y la tecnología alcanzan un nivel de integración suficiente como para convertirse en contenidos que se expresan en las prácticas generales de la sociedad y en componentes del sentido común de sus miembros y cómo estos contenidos se negocian y se articulan con otras formas de conocimiento" (OEI \& RICYT, 2003, p. 14), se trata, por tanto, de una categoría que evoca un atributo social que expresa la influencia del desarrollo científicotecnológico. En este contexto, los estudios de percepción social acerca de asuntos tecnocientíficos se han desarrollado básicamente a través de encuestas demoscópicas, no obstante, muchos autores coinciden en señalar la importancia de avanzar en el desarrollo de indicadores cualitativos y herramientas metodológicas correspondientes, que permitan enriquecer los procedimientos de acceso y el panorama cognitivo de los componentes actitudinales y valorativos de la cultura científica, así como incorporar el trasfondo social en el que las actitudes individuales se desarrollan.

Colombia no ha estado al margen de este interés investigativo y, a nivel internacional y, en consecuencia, ha emprendido, a través de Colciencias, la tarea de explorar las percepciones de sus ciudadanos al respecto, no obstante el país ha atravesado décadas de atraso tecnocientífico. Los imaginarios sociales constituyen un campo de interés en la política nacional de apropiación social del conocimiento, como requisito para la construcción de una sociedad del conocimiento. Hasta el momento, en Colombia se han efectuado dos encuestas de carácter nacional: la primera de ellas en el año 1994, propuesta por la "Misión de Ciencia, Educación y Desarrollo" y, la segunda, en el año 2004, publicada con el nombre: La percepción que tienen los colombianos sobre ciencia y Tecnología. Este último estudio es presentado con el siguiente argumento, mediante el cual es posible expresar la importancia y pertinencia de la presente propuesta investigativa:

Así, es decisión institucional de Colciencias declarar abierto este canal de comunicación mutua entre la política de ciencia, tecnología e innovación y la opinión ciudadana para continuar perfeccionando esta vasta y fundamental tarea de legitimación política y social del conocimiento, sin cuyo concurso no es, ni previsible ni imaginable, la evolución de la sociedad colombiana, en el contexto del mundo contemporáneo, y menos aún, del mundo futuro. (Colciencias, 2005, p. 12)

Así mismo, Bogotá, la capital colombiana, en el año 2001, fue observada en estos aspectos, en estudio realizado por Sandra Daza y, en el año 2007, en estudio comparativo de grandes núcleos urbanos junto con Buenos Aires (Argentina), Caracas (Venezuela), Madrid (España), Panamá (Panamá), São Paulo (Brasil) y Santiago (Chile).

\section{Características de la población encuestada en la Universidad de Caldas}

La población consultada de docentes y estudiantes de la Universidad de Caldas, con respecto al género, está constituida en un $50,7 \%$ por hombres y $49,3 \%$ por mujeres, integrantes de todas las áreas de conocimiento que tienen su asiento en la Institución y está distribuida proporcionalmente en ellas (Artes y Humanidades, Ciencias Jurídicas y Sociales, Ciencias Exactas y Naturales, Ciencias Agropecuarias y Ciencias para la Salud). 
El rango de edad de estudiantes encuestados está entre 16 y 39 años, con un promedio de 22 años. El rango de edad de los docentes encuestados está entre los 24 y 58 años, con un promedio de 43 años.

La situación socioeconómica, determinada por el estrato en el cual se encuentra ubicada la vivienda es muy diferente entre estudiantes y docentes, pues mientras el $79 \%$ de los estudiantes están ubicados en los estratos más bajos (1, 2 y 3$)$, el $72 \%$ de los docentes se encuentran ubicados en los estratos más altos $(4,5$ y 6$)$.

La procedencia fue indagada únicamente a la población estudiantil, la cual proviene fundamentalmente del departamento de Caldas (74,4\%), de cuyo total, la gran mayoría pertenece a sectores urbanos de este departamento $(93,2 \%)$. Aunque existe una gran diversidad en este aspecto, pues se advierte presencia de casi todos las regiones colombianas, la población estudiantil tiene su lugar de residencia familiar mayoritariamente en zonas urbanas $(94,2 \%)$ y en el municipio de Manizales (58\%), municipio en el que se encuentra la sede central de la Universidad de Caldas; del conjunto de estudiantes del departamento de Caldas, el $75 \%$ son de Manizales.

\section{Percepción acerca de la ciencia y la tecnología}

\subsection{Idea de ciencia y tecnología}

\section{Gráfica 1.}

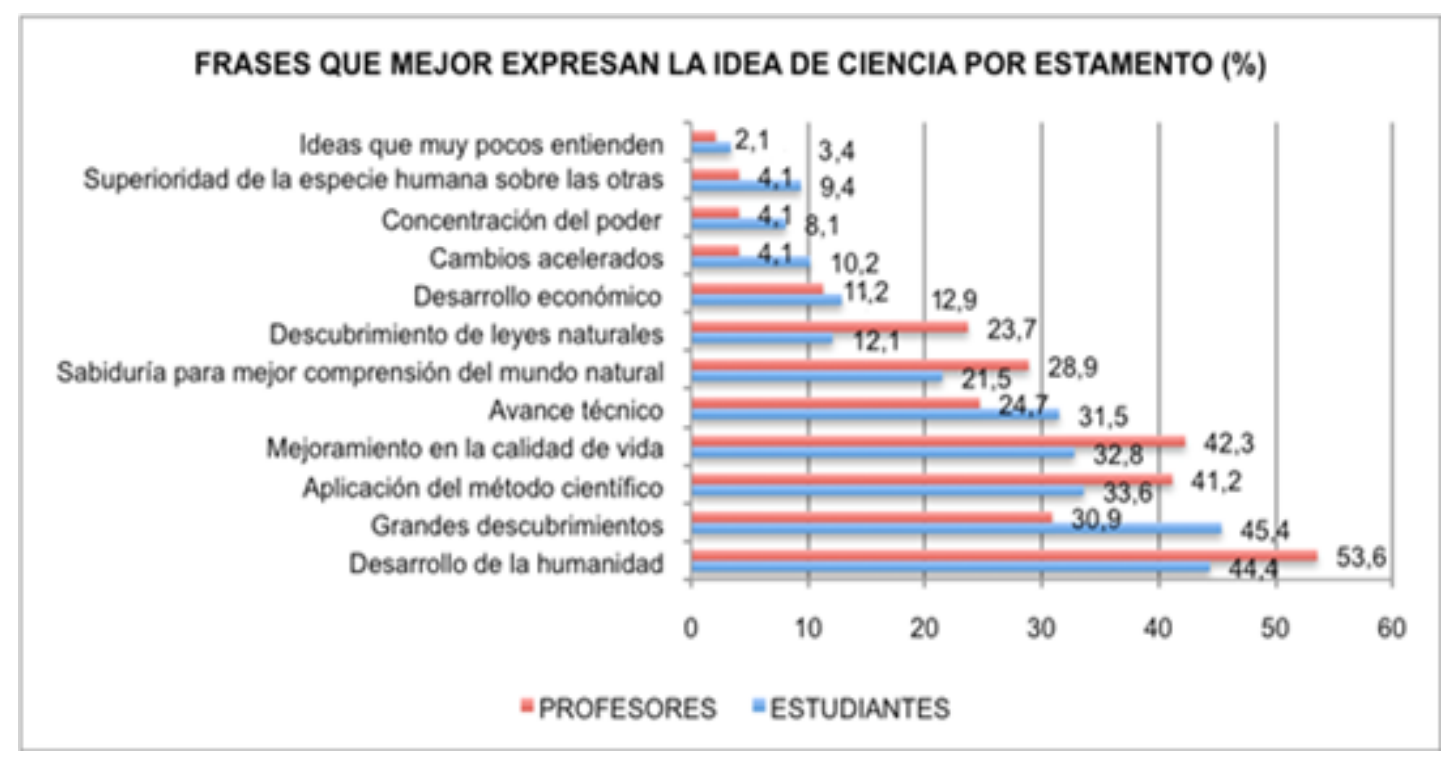

NOTA: puesto que los entrevistados tenían opción de elección múltiple, la sumatoria de los porcentajes excede el $100 \%$.

Como se advierte en la Gráfica 1, la idea de ciencia que mayoritariamente es compartida por docentes y estudiantes de la Universidad de Caldas es aquella que la asocia con efectos positivos para el desarrollo de la humanidad, particularmente, más de la mitad de los docentes se identifican con ella; seguidamente, se presenta la asociación un tanto mítica con grandes descubrimientos, con mayor presencia de estudiantes. En el conjunto de respuestas es clara la tendencia a ver la ciencia en función de su utilidad para el desarrollo social y el mejoramiento de la calidad de vida. Imágenes negativas 
referidas a la 'Concentración del poder' o a la generación de 'Ideas que muy pocos entienden' no tuvieron importancia visible en las respuestas, mientras que la asociación con una forma de conocer metódica tiene una presencia relevante. En las adhesiones a la idea de ciencia como fuente de 'Sabiduría para mejor comprensión del mundo actual', no se infiere un fuerte optimismo acerca del conocimiento científico.

Tendencia similar se presenta en las encuestas de Argentina, Brasil, España y Uruguay (2002-2003). Así mismo, el $41 \%$ de los docentes universitarios consultados en la Encuesta Nacional Colombiana (Colciencias, 2005, p. 99) asocian la idea de ciencia con el desarrollo de la humanidad.

\section{Gráfica 2.}

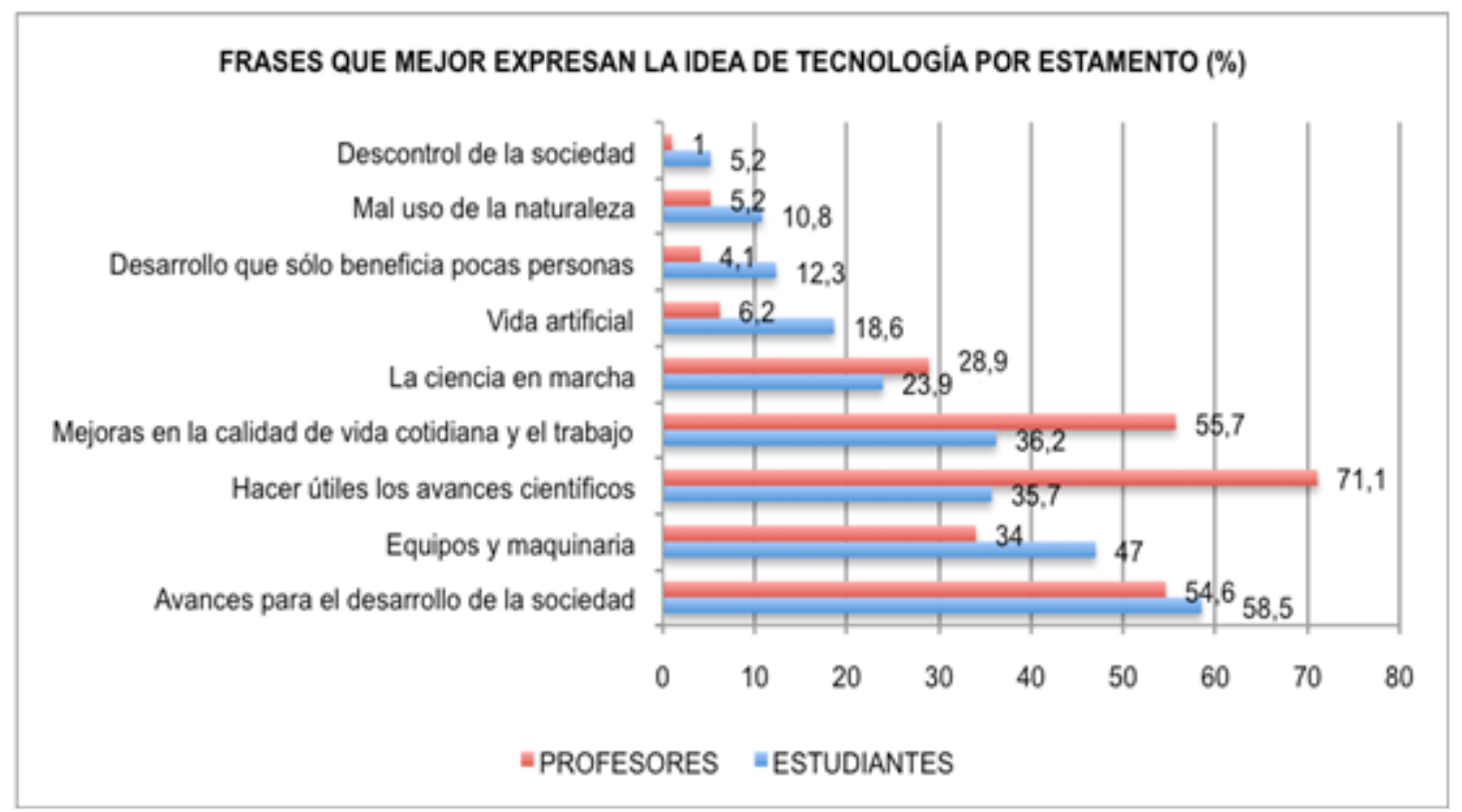

NOTA: puesto que los entrevistados tenían opción de elección múltiple, la sumatoria de los porcentajes excede el $100 \%$.

La idea de tecnología, así como la idea de ciencia, también tiende a vincularse con el desarrollo de la humanidad, pues un poco más de la mitad de docentes y estudiantes coincidieron en indicar esta asociación. Cabe resaltar que un porcentaje muy significativo de docentes $(71 \%)$ entiende la tecnología como aplicación del conocimiento científico, mientras que en los estudiantes no es tan fuerte esa imagen, como sí la asociación con artefactos y maquinarias. Las nociones que expresan valoraciones negativas acerca de la tecnología no tienen presencia importante en el conjunto de respuestas, dígase aquellas que se refieren a: la artificialidad de la vida, el mal uso de la naturaleza, el descontrol de la sociedad y la falta de equidad. No obstante, estas valoraciones negativas son poco relevantes, en ellas se advierte mayor presencia de la población estudiantil.

En este aspecto, las respuestas dadas por los docentes universitarios consultados en la Encuesta Nacional Colombiana (Colciencias, 2005, p. 100) presentan la misma tendencia de los docentes de la Universidad de Caldas; la respuesta que obtuvo más adhesión en la Encuesta Nacional corresponde a la asociación de idea de tecnología con 'Hacer útiles los avances científicos' (51\%), seguida de 'Avances para el desarrollo de la sociedad' (38\%). Adicionalmente, al igual que los docentes de la Universidad de Caldas, el grupo de docentes 
universitarios incluidos en la Encuesta Nacional muestra poca afinidad con aquellas ideas que implican valoraciones negativas acerca de la tecnología, por ejemplo, 'Mal uso de la naturaleza' (1\%), 'Desarrollo que beneficia a una pequeña proporción de personas' (1\%) y 'Vida artificial' (2\%).

\subsection{Valoración acerca de la ciencia y la tecnología en temas específicos}

Tabla 1.

\begin{tabular}{|l|c|c|c|}
\hline CALIFICACION OTORGADA A ALGUNOS POSIBLES EFECTOS DE LA CIENCIA Y LA \\
TECNOLOGIA, SEGUN ESTAMENTO \\
(calificación promedio en escala de l a 5)
\end{tabular}

La valoración a algunos aportes de la ciencia y la tecnología se realizó mediante calificación en la que se expresa el grado de acuerdo o desacuerdo con algunas afirmaciones polémicas o reactivos, los cuales fueron puntuados en una escala de 1 a 5 , donde 1 significa 'completo desacuerdo' y 5 'completo acuerdo'. Al respecto, aunque no se advierte demasiado optimismo, es clara la tendencia a valorarlas positivamente, especialmente como posibilidad en los campos de la salud y de la generación de mayor confort ${ }^{6}$, de la misma manera como se tiende a otorgarle una baja valoración a su capacidad para mejorar el ambiente y erradicar la pobreza y el hambre. Aunque las expectativas superan los temores, se advierte una actitud crítica que reconoce sin mucho entusiasmo sus bondades en unos aspectos y manifiesta claras reservas frente a otros; se trata, por tanto, de una comunidad que no se revela como pro-tecnocientífica. A juzgar por la coincidencia de estos resultados con todos aquellos que han arrojado las encuestas iberoamericanas, pareciera ser que los factores modeladores de la visión positiva de las tecnociencias se basan en la experiencia vital más fácil, cómoda y saludable, pero que, al mismo tiempo, la sensación de deterioro del ecosistema planetario hubiese operado como factor sensibilizador que ha contribuido a fisurar el optimismo y que, así mismo, los cuestionamientos al modelo económico capitalista que orquesta las notas del desarrollo científico y tecnológico estarían aportando a la generación de cierto pesimismo con respecto a la capacidad de limar las desigualdades sociales y mejorar las condiciones laborales. Desde este punto de vista, cabría afirmar la existencia de mayor conciencia acerca de los valores empresariales y económicos del capitalismo insertos en el núcleo de la actividad tecnocientífica; entiéndase que las universidades, especialmente las públicas, son escenarios intensivos en actividades debates, análisis y críticas al modelo capitalista.

No obstante lo anterior, se observa con claridad que los docentes tienden a presentar valoraciones más altas y, por ende, una actitud más esperanzadora frente a las tecnociencias que los estudiantes, quienes en sus calificaciones muestran mayor escepticismo, aunque estadísticamente las diferencias no son significativas ${ }^{7}$. Se trata de dos poblaciones que tienen grandes contrastes (véase 
sección 2.) en cuanto a edad, nivel educativo y situación socioeconómica, variables que podrían estar interviniendo en tal valoración. Si se comparan las calificaciones promedio que indican el grado de adhesión a cada una de estas afirmaciones en la escala antedicha, se observa que en los estratos más altos hay una actitud más optimista que en los estratos más bajos, aunque las diferencias entre ellos no son estadísticamente significativas ${ }^{8}$ y al correlacionar la edad con la calificación promedio otorgada en cada reactivo, se encuentra que la relación es inestable y muy débil, oscila entre $+0,2$ y $-0,2$.

Ahora bien, continuando con las valoraciones otorgadas a los aportes de la ciencia y la tecnología en algunos temas específicos, cabe examinar el comportamiento de dichas calificaciones con respecto a la religiosidad. Un poco más de la mitad de la población universitaria consultada se declaró católica (56.5\%), algo más de una cuarta parte no perteneciente a religión alguna (25.9), un $9 \%$ se agrupa en otras filiaciones (Hare-krishna, Hiálico, Metafísico, Mormón, Cosmología, Pentecostal, Testigo de Jehová) y, finalmente, un $8,6 \%$ no dio respuesta a esta pregunta (sólo el $38,7 \%$ de quienes admiten su pertenencia a alguna religión se declaran practicantes). Al comparar las calificaciones otorgadas a los reactivos que expresan algunos aportes de las tecnociencias entre estas categorías de religiosidad se advierte coincidencia, es decir que no se encontró diferencia significativa entre los valores de autoposicionamiento religioso en las respuestas (o sea que los valores promedio dados a las preguntas fueron estadísticamente iguales ${ }^{9}$ ), como tampoco entre quienes se declaran practicantes y quienes no, lo que indica que el factor religioso no se correlaciona con la actitud hacia la ciencia y la tecnología.

Al observar las calificaciones a los aportes de las tecnociencias dadas por la población encuestada con respecto a los diferentes campos del saber, determinados por la pertenencia a cada una de las áreas del conocimiento que tienen su asiento en la Universidad de Caldas y se expresan en sus Facultades, se advierte cierta homogeneidad, salvo en los siguientes casos (obsérvese tabla contigua): en Ciencias Jurídicas y Sociales existe menor temor por la pérdida de puestos de trabajo que la reconversión tecnológica supone (recuérdese que es un ítem negativo); en Ciencias para la Salud e Ingeniarías se presenta mayor adhesión a los efectos de las tecnociencias en términos de su capacidad para hacer la vida más fácil y cómoda; en Artes y Humanidades se advierte menor convicción acerca de las posibilidades que ofrece para erradicar el hambre y la pobreza en el mundo; mientras en salud se presenta menor confianza frente a sus efectos en el cierre de la brecha entre países ricos y pobres, en ingeniería se advierte mayor convicción al respecto (ítem negativo); y, en Salud, de manera obvia, se presenta un mayor optimismo frente a su posibilidad para curar enfermedades y hacer la vida más sana.

Tabla 2. 


\begin{tabular}{|c|c|c|c|c|c|c|}
\hline \multicolumn{7}{|c|}{$\begin{array}{l}\text { CALIFICACION OTORGADA A ALGUNOS POSIBLES EFECTOS DE LA } \\
\text { Y LA TECNOLOGIA, SEGÚN ÁREA DEL CONOCIMIENTO } \\
\text { (calificación promedio en escala de } 1 \text { a } 5 \text { ) }\end{array}$} \\
\hline & 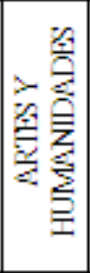 & 急 & 终 & 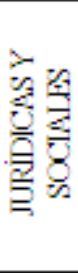 & 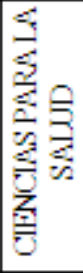 & 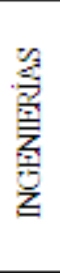 \\
\hline Curar enfermedades y hacer la vida más sana. & 3,6 & 3,8 & 3,8 & 3,8 & 4,1 & 3,9 \\
\hline Perder puestos de trabajo. & 3,4 & 3,4 & 3,1 & 2,9 & 3,3 & 3,4 \\
\hline Mejorarla calidad de vida para las generaciones futuras. & 3,2 & 3,5 & 3,3 & 3,4 & 3,6 & 3,5 \\
\hline Crear un estilo de vida artificial. & 3,4 & 3,5 & 3,5 & 3,5 & 3,3 & 3,4 \\
\hline Hacer la vida sea más fácil y cómoda. & 3,5 & 3,6 & 3,5 & 3,5 & 4,0 & 4,1 \\
\hline Erradicar la pobreza y el hambre en el mundo. & 2,0 & 2,2 & 2,4 & 2,4 & 2,2 & 2,4 \\
\hline Mejorar el medio ambiente. & 2,4 & 2,4 & 2,5 & 2,5 & 2,4 & 2,6 \\
\hline Ahondar la brecha entre paises ricos y pobres. & 3,2 & 3,3 & 3,5 & 3,5 & 3,8 & 2,8 \\
\hline
\end{tabular}

Con respecto a estas calificaciones en algunos campos o temáticas específicas, es posible llamar la atención sobre el ámbito o trasfondo social y cultural desde el cual éstas se desarrollan, en tanto, el contexto y experiencia vital de los sujetos es ingrediente fundamental para inclinar los conceptos hacia uno u otro lado de las escalas valorativas. Sobre este aspecto, Cristóbal Torres (2005), a partir de criterios construidos por el análisis comparativo de diversas encuestas internacionales, estima que:

La familiaridad con la tecnociencia crea formas evaluativas en las que, a la vez que se reconoce su importancia y relevancia en determinados logros alcanzados en campos como la medicina o el trabajo, que contribuyen decisivamente a permitir una vida de progreso y bienestar, también se generan unas actitudes de cautela, pragmatismo y distancia que asumen sus logros conseguidos pero que, a la vez, consideran sus actuales consecuencias negativas y sus riesgos potenciales de futuro. Lo cual puede llevar, entre otras posibilidades a un posicionamiento crítico contra cualquier iniciativa que se entienda como legitimadora de una pretendida condición inmaculada de la tecnociencia. Por el contrario, los ciudadanos de los países con un menor nivel de desarrollo, e históricamente con una menor experiencia cotidiana con la tecnociencia, pueden mostrar una mayor indiferencia por ignorancia hacia los temas de la ciencia y la tecnología, pero también pueden desarrollar una pauta de apuesta optimista para que este factor permita el equiparamiento con aquellas sociedades más avanzadas que, en su entorno, les sirven de referencia. (p. 35)

\subsection{Valoración general acerca de la ciencia y la tecnología}

En los estudios acerca de la percepción pública sobre las tecnociencias, es recurrente la pregunta en la que se solicita un balance general entre los beneficios y los perjuicios ocasionados por el uso de las ciencias. Al respecto (Gráfica 3), en el conjunto de la población prevalece la idea de que los beneficios y los perjuicios de la ciencia se encuentran equilibrados, es decir que se reconocen tanto sus riesgos como sus bondades (35,3\%). En concordancia con las respuestas anteriores, los docentes muestran una actitud más confiada y optimista frente a las consecuencias de la actividad científica $(55,7 \%)$ que los estudiantes

$(24,2 \%)$.

No obstante, se presenta una postura general en la que se advierte conciencia 
de riesgo en dos terceras partes de la población consultada, la cual se relaciona en diferente grado de intensidad con algunas otras variables socio-demográficas (como más adelante se indica), pues la percepción pública del riesgo es explicable a partir de aristas sociológicas y culturales en tanto los intereses y valores (individuales y sociales) y los patrones culturales moldean la mirada de los sujetos al respecto.

\section{Gráfica 3.}

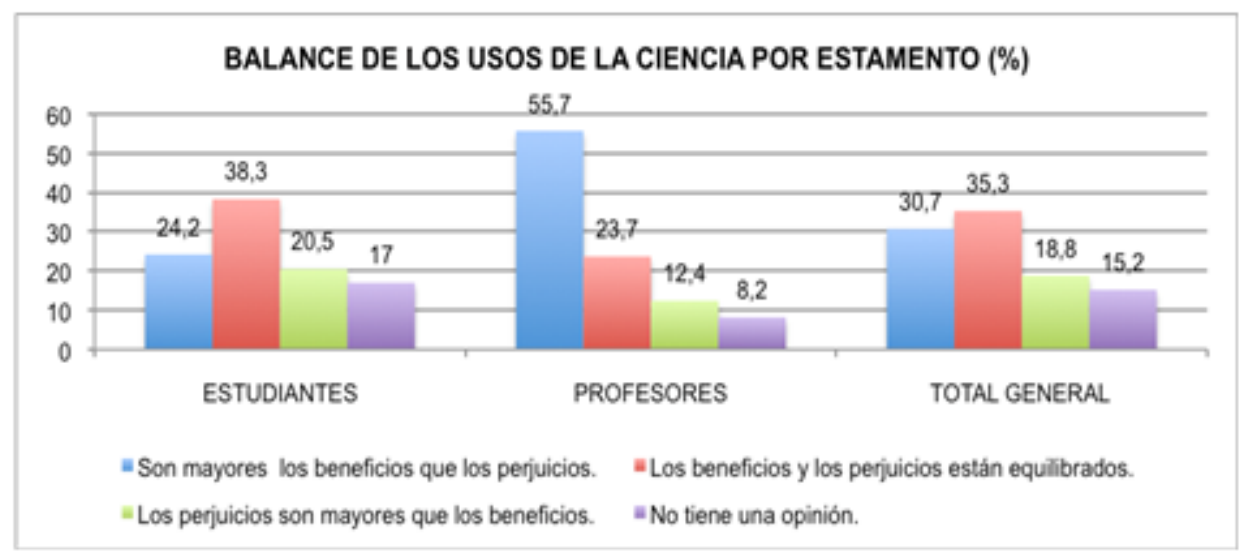

Al relacionar las respuestas sobre el balance de los usos de la ciencia con otras variables socio-demográficas, se advierte lo siguiente:

No se encuentran importantes diferencias en las respuestas al distribuirlas por filiación religiosa, aunque quienes se declaran pertenecientes a otras religiones diferentes a la católica son un poco menos optimistas.

Una posición algo más reservada en las mujeres, quienes, en menor proporción que los hombres, estiman que son mayores los beneficios. Así mismo, es mayor la proporción de mujeres frente a los hombres que consideran equilibrados los bondades y los riesgos, y las que consideran mayores los perjuicios.

\section{Gráfica 4.}

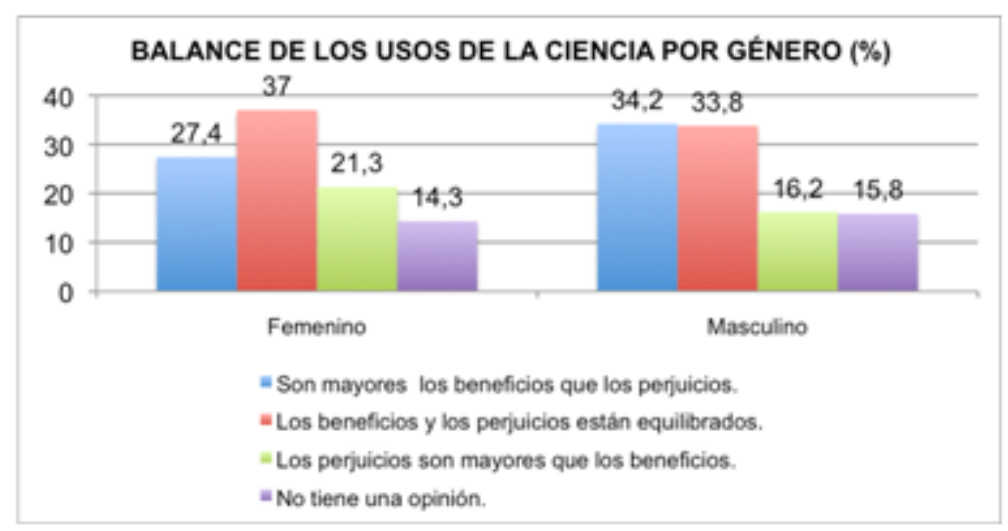

La población encuestada perteneciente a los estratos más altos tiende a ser más optimista. Mientras el $62,5 \%$ de las personas de estrato 6 consideran que son mayores los beneficios, esta opinión sólo es compartida por el $18,2 \%$ de las personas de estrato 1; de la misma manera, mientras el $31,8 \%$ de los universitarios de estrato 1 se inclinan a pensar que son mayores los perjuicios, esta idea corresponde al $6,2 \%$ en el estrato 6 (ver tabla 4). Esta tendencia es 
también observada en las encuestas iberoamericanas, lo que ha permitido suponer que:

La posición socioeconómica, clase social e ingresos familiares, también son determinantes; tienden a ser los individuos de posiciones socioeconómicas bajas los más negativos, mientras que los de clase media alta y alta o de ingresos medio altos y altos tienen percepciones mayoritariamente positivas. Resulta lógico si tenemos en cuenta que los segmentos mejor posicionados económicamente son los que tienen más acceso y mayor familiaridad con las nuevas tecnologías, así como un nivel de estudios más alto que aproxima más a la ciencia. (Arrollo, 2007, p. 110)

Tabla 3.

\begin{tabular}{|l|c|c|c|c|c|c|}
\hline \multicolumn{7}{|c|}{ BALANCE DE LOS USOS DE LA CIENCIA POR ESTRATO SOCIO-ECONOMICO (\%) } \\
\hline & $\begin{array}{c}\text { Estrato } \\
1\end{array}$ & $\begin{array}{c}\text { Estrato } \\
2\end{array}$ & $\begin{array}{c}\text { Estrato } \\
3\end{array}$ & $\begin{array}{c}\text { Estrato } \\
4\end{array}$ & $\begin{array}{c}\text { Estrato } \\
5\end{array}$ & $\begin{array}{c}\text { Estrato } \\
6\end{array}$ \\
\hline Mayores los beneficios que los perjuicios. & 18,2 & 20,0 & 24,0 & 41,0 & 46,7 & 62,5 \\
\hline Beneficios y perjuicios equilibrados. & 31,8 & 39,0 & 44,8 & 25,3 & 23,3 & 12,5 \\
\hline Perjuicios mayores que los beneficios. & 31,8 & 20,0 & 16,7 & 24,1 & 20,0 & 6,2 \\
\hline No tiene una opinion. & 18,2 & 21,0 & 14,6 & 9,6 & 10,0 & 18,7 \\
\hline Total & 100 & 100 & 100 & 100 & 100 & 100 \\
\hline
\end{tabular}

En la Facultad de Ciencias Exactas y Naturales se presenta mayor conciencia de los riesgos de los usos de la ciencia (34\%) y en la Facultad de Ciencias Agropecuarias menor conciencia de ello (12\%). En la Facultad de Ciencias Jurídicas y Sociales hay mayor confianza en sus beneficios $(31,4 \%)$ y en la Facultad de Ingeniería se observa la mayor proporción de respuestas $(51,2 \%)$ en las que se consideran equilibradas sus bondades y riesgos. Una posición algo más reservada en las mujeres, quienes, en menor proporción que los hombres, estiman que son mayores los beneficios.

En la escala de autoposicionamiento político no es clara la tendencia, pues los resultados se presentan irregulares y no se observa alguna dirección lineal en la escala de respuestas (el autoposicionamiento político fue identificado mediante ubicación en una escala en la que cero corresponde a extrema derecha y diez corresponde a la extrema izquierda).

\section{Gráfica 5.}

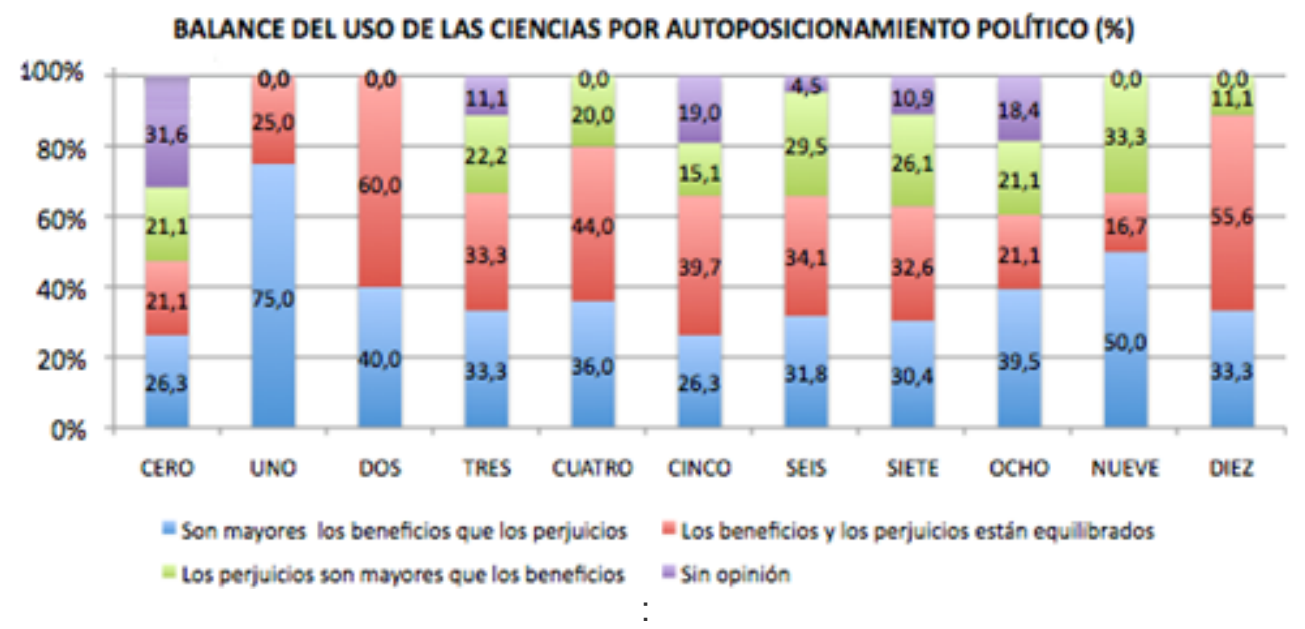


La actitud hacia la búsqueda de información sobre ciencia y tecnología se encuentra relacionada con la favorabilidad hacia éstas, pues en aquellas personas interesadas en la búsqueda autónoma de información se advierte un balance más positivo sobre las tecnociencias que en aquellas que no lo están. Esta correlación positiva entre mayor información y mayor aceptación a la ciencia y la tecnología, aunque ha sido tema de mucha controversia, dadas las diversas interpretaciones que suscita, lo cierto es que los resultados de la mayoría de las encuestas generadas en diversos contextos tienden a ratificarla, de ahí la confianza que se otorga a las actividades de divulgación y difusión científica por su supuesta capacidad para fomentar actitudes generales más positivas.

Las diferencias de opinión encontradas entre estudiantes y docentes hace explícita la correspondencia entre el nivel educativo y la imagen de la ciencia, pues estos últimos tienen un nivel superior de escolaridad y valoran más positivamente los usos de la ciencia; y los estudiantes, quienes poseen menos escolaridad tienden a una percepción más negativa. Esta idea de concordancia entre nivel educativo (conocimiento - alfabetización científica) y la imagen de las tecnociencias, que opera como importante predictor de actitudes positivas o negativas, corresponde al llamado modelo ilustrado que vincula de forma lineal la actitud con el conocimiento, el cual ha sido objeto de análisis sistemático mediante las comparaciones entre países y el seguimiento histórico a los resultados de diversas encuestas. No obstante la correlación suele ser positiva, se ha encontrado que en la Unión Europea es menos intensa que en Canadá, en Estados Unidos y Japón es más fuerte, aunque no estadísticamente significativa, salvo el caso de Canadá (Torres, 2005). En tales análisis se han realizado exámenes discriminados por respuestas a diferentes tipos de preguntas y se ha encontrado que la correlación es más baja en asuntos referidos al papel de la tecnociencia para erradicar la pobreza, crear empleo y hacer inagotables los recursos naturales, lo que ha permitido concluir que no existe una relación de dependencia entre las valoraciones meliorativas y los altos niveles de alfabetización tecnocientífica, esta relación sólo opera en algunos tópicos específicos y es variable en diferentes contextos socioeconómicos. Torres (2005), refiriéndose a la inexistencia de un modelo estable para identificar la relación entre los niveles de instrucción y las representaciones sociales de la tecnociencia, ilustra que:

Durant, Bauer, Gaskell, Miden, Liakopoulos y Schoten (2000), a partir del análisis de los datos del Eurobarómetro de 1992, han señalado que la variabilidad de los datos actitudinales en los distintos países permite afirmar que la estructuración de los mismos obedece a una lógica más amplia, en la que el factor alfabetización científica no interviene en exclusiva y su impacto sólo alcanza un determinado umbral y en algunos aspectos concretos. (p. 34)

Se estima, además, que intervienen de manera importante en las valoraciones otros factores, no necesariamente correlacionados con el nivel educativo, tales como los ideales de justicia social, progreso humano y salud, así como el asentimiento con la transformación de la naturaleza en la forma como se ha venido dando.

En la Encuesta Nacional Colombiana (Colciencias, 2005, p. 102), se observa que el $81 \%$ de los empresarios consultados consideran que los beneficios de la ciencia y la tecnología son mayores que los efectos negativos, mientras que esta opinión es compartida por el $73 \%$ de los docentes universitarios e idéntica proporción de personas en los grupos de público en general y de docentes de básica y media. Ahora bien, en la encuesta desarrollada en los grandes núcleos urbanos iberoamericanos en 2008, se encontró que: "sólo los individuos con 'escolaridad superior' consideran de forma mayoritaria que la ciencia y la tecnología tienen 'muchos riesgos y muchos beneficios'" (FECYT, OEI et al, 
2009 , p. 43). Estos datos aportarían al cuestionamiento realizado al modelo ilustrado que correlaciona en forma lineal la actitud favorable y la escolaridad.

Ahora bien, esta actitud reservada, aparentemente ambivalente y dicotómica, de la comunidad académica de la Universidad de Caldas con respecto a la ciencia y la tecnología, parece aclararse más cuando se observan las respuestas acerca de aquellos campos en los cuales se cree que se enfoca prioritariamente el desarrollo tecnocientífico, la idea acerca del manejo de la ciencia en el mundo y la accesibilidad de la ciencia al público.

\subsection{Concepto acerca de los campos de mayor desarrollo tecnocientífico}

\section{Gráfica 6.}

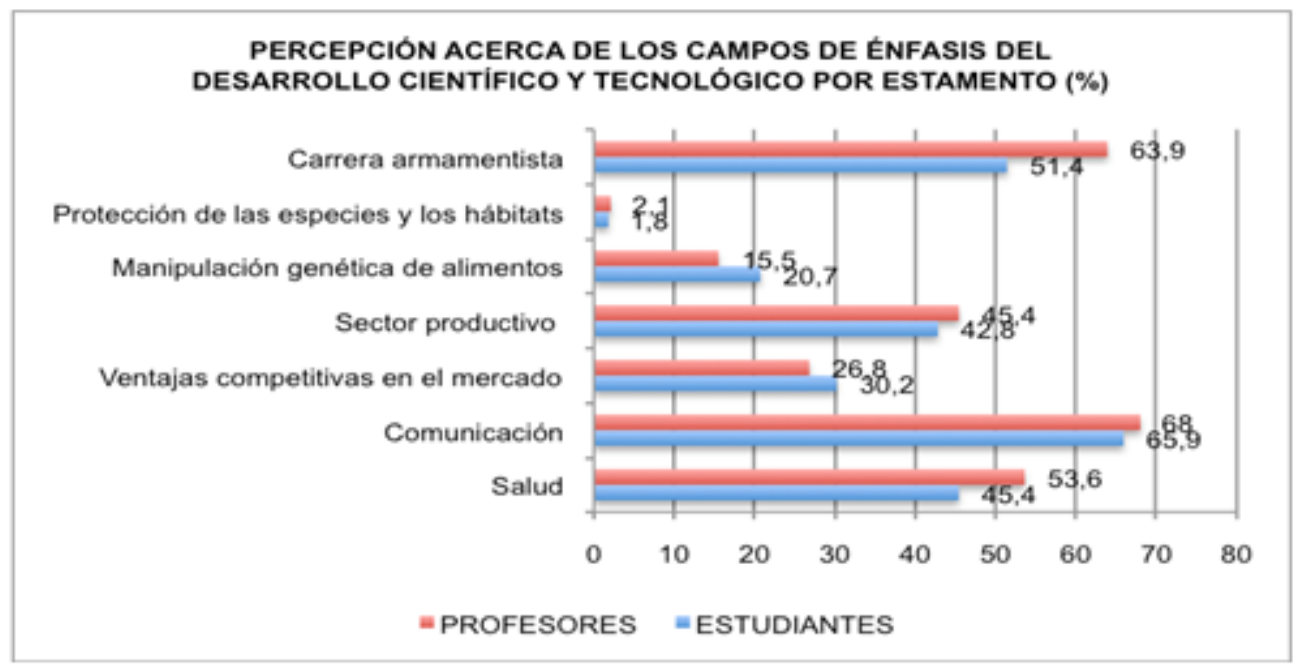

NOTA: puesto que los entrevistados tenían opción de elección múltiple, la sumatoria de los porcentajes excede el $100 \%$.

Como se advierte en la Gráfica 6, los docentes y estudiantes en proporciones similares coinciden en señalar, en su orden, las comunicaciones, la carrera armamentista, la salud y el sector productivo como aquellos campos en los que se centra preferencialmente el desarrollo de la ciencia y la tecnología, lo cual, sumado a la muy insignificante aparición de respuestas en torno a la protección de las especies y el hábitat, nos ratifica que en este grupo poblacional se presenta una actitud crítica no maniquea en la que se reconoce la naturaleza dual de la ciencia y la tecnología; en tal sentido, se admiten, por una lado, sus beneficios en los aspectos enunciados (salud, comunicación y productividad) que, en parte, podrían explicar las anteriores asociaciones con el desarrollo humano y social, pero, por otro lado, se evidencian riesgos en su potencialidad para destruir la vida humana y no se le otorga confianza a su capacidad para preservar la naturaleza. Como lo plantea Cristóbal Torres (2005), el incremento en los conocimientos en asuntos tecnocientíficos no necesariamente implica su correlato en actitudes positivas, sino más bien un refuerzo de las representaciones ambivalentes. También hay que entender que en tanto el contexto de aplicación de las tecnociencias es la sociedad y allí hacen presencia pluralidad de valores y agentes evaluadores, los asentimientos y conflictos aumentan exponencialmente. En palabras de Javier Echeverría (2003, p. 234): "Es literalmente imposible dilucidar si la tecnociencia es buena o mala para la sociedad, en primer lugar porque hay muchas sociedades y muchas 
tecnociencias, pero ante todo porque la diversidad de sistemas de valores ${ }^{11}$ es mucho mayor en el contexto de aplicación social de la tecnociencia".

\subsection{Ideas acerca del manejo de la ciencia en el mundo}

En este aspecto, docentes y estudiantes también coinciden en las mismas ideas acerca del manejo de la ciencia en el mundo. Vistas las respuestas de estos dos grupos poblacionales en conjunto, en una pregunta de opción múltiple, la gran mayoría $(76,2 \%)$ corresponde a la idea de que ésta corre por cuenta de los países ricos, seguidamente, también en una proporción mayoritaria $(65,1 \%)$, a las grandes empresa multinacionales, el $19,2 \%$ de las respuestas se enfocan a la demanda espontánea del mercado, el $16,1 \%$ a los propios científicos y el $1 \%$ a las universidades. Es claro entonces, que el desarrollo de la ciencia no se percibe como una actividad próxima, correspondiente con las condiciones específicas del entorno desde el cual se generan las respuestas (región-país), lo que permite hacer alusión nuevamente al carácter situado de las percepciones sociales y a la manera como se concretan las representaciones de las personas a partir de la inserción en determinadas dinámicas sociales y culturales. Llama la atención que los autores de estas respuestas aunque son miembros de una institución de Educación Superior Universitaria que, por su naturaleza, se orienta a la generación, difusión y transferencia del conocimiento a través de la investigación, la docencia y la extensión, no perciben a las universidades como actores significativos en el desarrollo científico y tecnológico, a pesar de que, a diferencia de las países desarrollados, en América Latina y el Caribe las universidades, especialmente las públicas, son las protagonistas principales de la práctica investigativa, aunque es clara la fragilidad de sus nexos con la empresa privada, el Estado y la sociedad civil, lo que indica su exiguo aporte a los procesos de apropiación social del conocimiento y, por ende, a la generación de aplicaciones en los procesos sociales y económicos. Para el año 2008, en Colombia, el $57,3 \%$ de los investigadores y el $48,3 \%$ de los grupos de investigación activos pertenecían a Instituciones de Educación Superior Públicas (Observatorio Colombiano de Ciencia y Tecnología, 2009a, p. 51, 53) (ver Gráfica 7).

\section{Gráfica 7.}

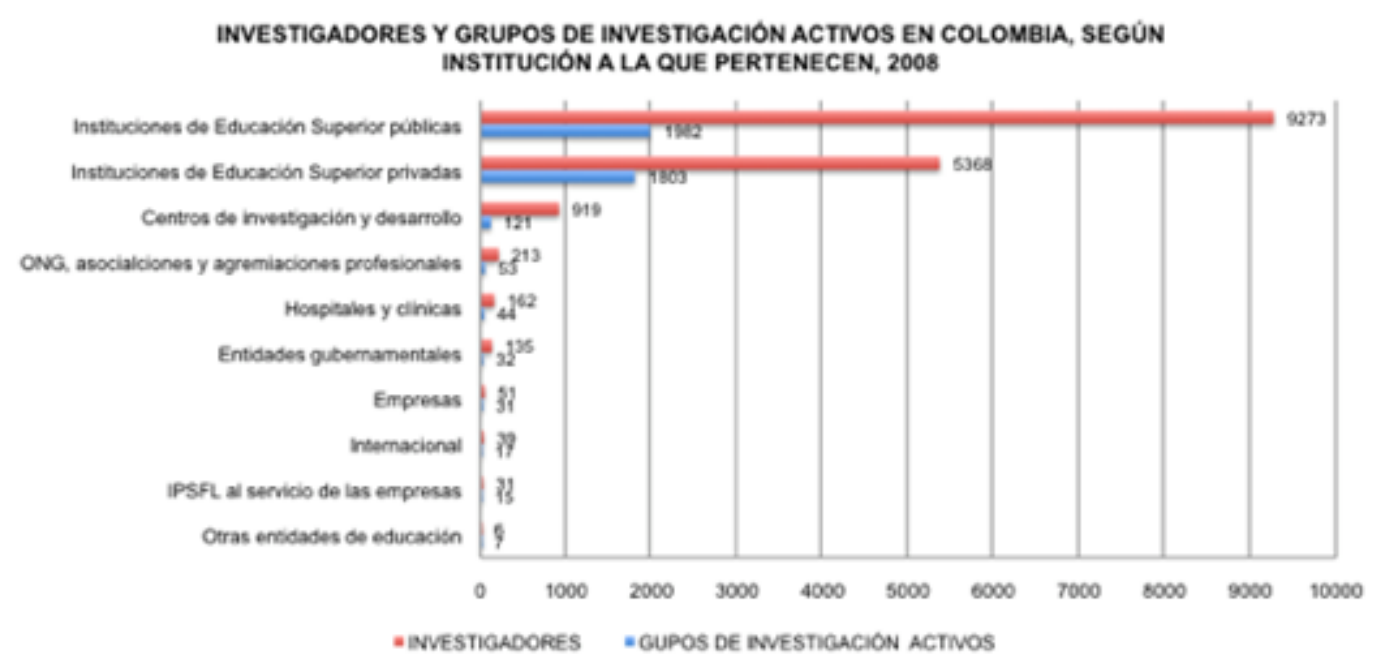

Fuente: Observatorio Colombiano de Ciencia y Tecnología. Indicadores de ciencia y tecnología, Colombia 2009. 
En medio de la precariedad en el campo de la I+D, en América Latina y el Caribe, en la última década, se han registrado importantes logros, atribuibles a la inversión pública (presencia de artículos científicos en bases de datos internacionales y formación universitaria en los niveles de pregrado, maestría y doctorado), sin embargo, éstos aún no han logrado eficacia transformadora; situación que tiene que ver tanto con el tradicional aislamiento del sector científico con respecto a la sociedad, como con la debilidad en la inversión y en la demanda de conocimientos por parte de las empresas, a las que se le señala una enorme deuda social en este aspecto.

\subsection{Concepto acerca de la accesibilidad de la ciencia y la tecnología al público}

El $83,6 \%$ de la población universitaria consultada opina que la ciencia y la tecnología no son de fácil acceso al público en general, lo cual obviamente obedece, al menos, a dos factores. El primero de ellos, corresponde a las particularidades del contexto nacional y regional en el campo educativo, pues sumado al tema de la cuestionada calidad, la pirámide educativa colombiana muestra que sólo un grupo muy selecto de estudiantes accede a las instituciones de Educación Superior. El segundo, se refiere al aún inmaduro proceso nacional de popularización de la ciencia o divulgación científica con fines de apropiación social del conocimiento científico. Ahora bien, recuérdese que ante la consulta acerca de la idea de ciencia (Grafica 1), un porcentaje muy reducido de universitarios $(3,1 \%)$ la asoció con 'Ideas que muy pocos entienden', lo que podría explicarse por el nivel de escolaridad de quienes respondieron, es decir, universitarios, sin embargo, al indagar acerca de la integración de la actividad científica con la sociedad en términos de accesibilidad al público en general, la situación cambia radicalmente.

\subsection{Valoración de la profesión de científico}

Otro de los aspectos de indagación presente en la gran mayoría de las encuestas de percepción acerca de la ciencia y la tecnología, es la imagen que se tiene de los científicos y la valoración que se realiza de esta profesión; éste es un aspecto relevante en el ámbito de las políticas de promoción de las carreras científicas e investigativas, en tanto se estima necesario que éstas sean vistas de manera positiva y se las perciba como una salida profesional interesante, como una condición necesaria para la dotación de recursos humanos requeridos para la consolidación de sociedades del conocimiento. Se considera que este aspecto es uno de los más sensibles a los marcos de referencias de los encuestados, pues, en este caso, se trata de una población que en la cotidianidad de la vida académica se encuentra próxima a la actividad científica e investigativa en condición de alumnos y docentes de asignaturas de investigación, de miembros de semilleros y/o grupos de investigación y de interlocutores permanentes con personas de la Institución y fuera de ella dedicadas a actividades investigativas. 


\section{Gráfica 8.}

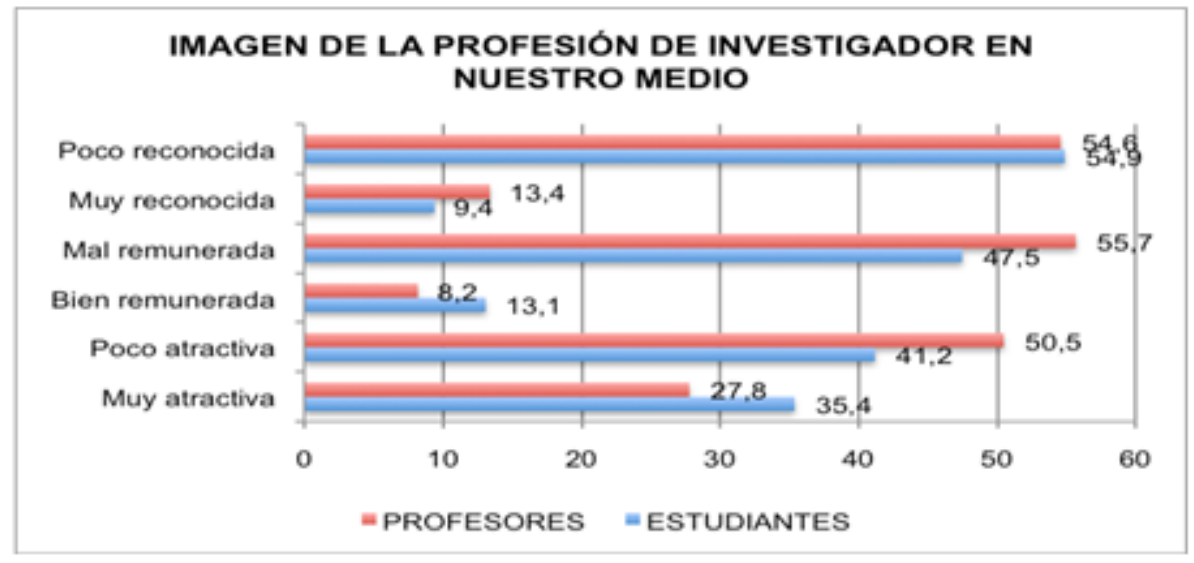

NOTA: puesto que los entrevistados tenían opción de elección múltiple, la sumatoria de los porcentajes excede el $100 \%$.

\section{Gráfica 9.}

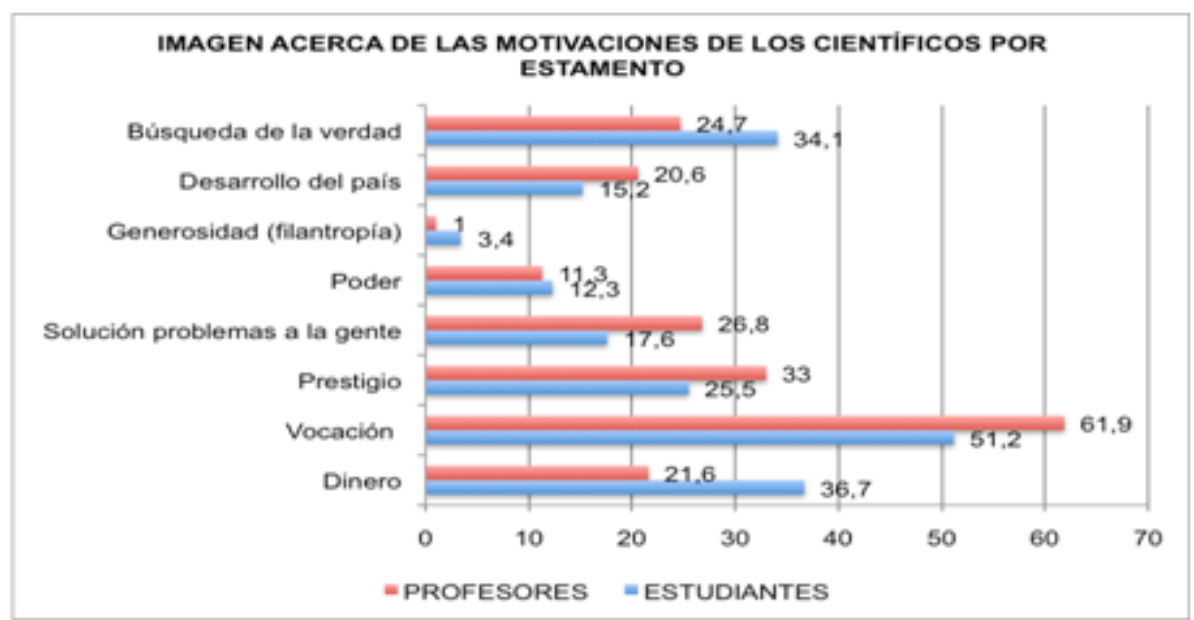

NOTA: puesto que los entrevistados tenían opción de elección múltiple, la sumatoria de los porcentajes excede el $100 \%$.

A la consulta sobre la imagen de la profesión del investigador en nuestro medio, tanto docentes como estudiantes muestran un patrón de respuesta orientado hacia una mala valoración. Más del $50 \%$ de los docentes la consideran poco reconocida, mal remunerada y poco atractiva. Aunque los estudiantes coinciden con los docentes acerca del no reconocimiento social de ésta, en ellos $(35,4 \%)$ se observa que esta profesión se presenta un poco más atractiva que en los docentes (27,8\%); por consiguiente, en este aspecto, la relación de menor atracción hacia la profesión de investigador es inversa a la edad, a la escolaridad y al estrato socioeconómico. Estas respuestas explican la razón por la cual ante la pregunta sobre las motivaciones que tienen los científicos para dedicarse a su trabajo predomina la vocación $(61,9 \%$ de los docentes y $51,2 \%$ de los estudiantes) sobre otro tipo de incitaciones tales como: el dinero, la búsqueda de la verdad, el prestigio, la solución de los problemas de la gente, el desarrollo del país y la filantropía. Es posible sugerir que estos conceptos se nutren del 
imaginario social acerca de la baja calidad del mercado de trabajo de los científicos en el entorno, así como de la predominante percepción sobre el poco desarrollo de la ciencia en la región (departamento de Caldas) (64,8\% del total de la población), atribuido fundamentalmente a la baja inversión estatal en ciencia y tecnología (38,3\%). Al respecto cabría señalar, sin más palabras, la sumatoria de atrasos que terminan haciendo presencia en la región: en 2007, América Latina y el Caribe participaban con el 2,2\% de la inversión mundial en I+D; en ese mismo año, Brasil, México, Argentina y Chile poseían el $92,6 \%$ de la inversión de América Latina y el Caribe, mientras que en el restante $7,4 \%$ se encuentran los demás países, incluida Colombia (REDES, RICYT, OCTS, 2009). Obsérvese, además, la situación del departamento de Caldas con respecto a otras regiones del país.

Tabla 4.

\begin{tabular}{|c|c|c|c|c|c|}
\hline \multicolumn{6}{|c|}{$\begin{array}{l}\text { DEPARTAMENTO DE CALDAS CON RESPECTO A BOGOTA Y ANTIOQUIA } \\
\text { EN INDICADORES DE CIENCIA Y TECNOLOGIA }\end{array}$} \\
\hline REGION & $\begin{array}{l}\text { POBLACTON } \\
(2005) \\
(\text { como \% dal } \\
\text { totel nacional) }\end{array}$ & $\begin{array}{l}\text { IVESTIGACION } \\
\text { YDESARROLLO } \\
(2000-2007) \\
\text { (como \% dal total } \\
\text { nacional) }\end{array}$ & $\begin{array}{l}\text { ACITVDADES } \\
\text { ENCRECAA, } \\
\text { IECNOLOGIA } \\
\text { E } \\
\text { NNOVACION } \\
(2000-2007) \\
\text { (como \% dil } \\
\text { totel nacional) }\end{array}$ & $\begin{array}{c}\text { GRUPOSDE } \\
\text { NVESTIGACION } \\
\text { ACTIVOS }(2007) \\
\text { (como \% dal tot l } \\
\text { nacional) }\end{array}$ & $\begin{array}{l}\text { AVESTIGADORES } \\
\text { ACTIVOS (2007) } \\
\text { (como \% dd total } \\
\text { nacional) }\end{array}$ \\
\hline $\begin{array}{l}\text { DEPARTAMENTO } \\
\text { DE CALDAS }\end{array}$ & 2,3 & 3,1 & 3,1 & 2,0 & 4,3 \\
\hline $\begin{array}{l}\text { BOGOTA } \\
\text { DISTRITO } \\
\text { CAPITAL } \\
\end{array}$ & 15,9 & 53,9 & 57,2 & 37,2 & 39,4 \\
\hline $\begin{array}{l}\text { DEPARTAMENTO } \\
\text { DE ANTIOQUIA }\end{array}$ & 13,2 & 23,9 & 17,8 & 15,1 & 19,4 \\
\hline
\end{tabular}

FUENTES: Observatorio Colombiano de Ciencia y Tecnología, Indicadores de ciencia y tecnología 2008; y DANE -Departamento Administrativo Nacional de Estadística- (2006).

Continuando con la imagen acerca de la profesión de investigador, los docentes y estudiantes de la Universidad de Caldas muestran una tendencia de opinión diferente a la encontrada en los estudios iberoamericanos de más reciente publicación consultados, pues se presentan menos atraídos hacia la profesión de investigador:

- La encuesta realizada en Bogotá (Daza, 2008, p. 28-29) presenta la profesión científica bastante bien valorada $(66,5 \%)$, se la reconoce como prestigiosa, pero no se percibe como bien remunerada ni tampoco como lo suficientemente atractiva para los jóvenes; en esta última opinión, los porcentajes se elevan a medida que se asciende en edad, escolaridad y estrato.

- En la última Encuesta Nacional Española (FECYT, 2009), se aprecia que los ciudadanos poseen una imagen positiva sobre la ciencia como profesión, la profesión de investigador se ve muy atractiva para los jóvenes y con un alto reconocimiento social, aunque no se admite que sea bien remunerada. La búsqueda de nuevos conocimientos y el poder ayudar a solucionar problemas sociales son, a juicio de los españoles, las principales motivaciones que llevan a dedicarse a la investigación. Concepto que se advierte más positivo que en las encuestas anteriores. 
- En la encuesta realizada en los principales centros urbanos latinoamericanos (FECYT, 2009, p. 106-107), se encuentra que casi la mitad de los encuestados considera que la profesión de científico es atractiva para los jóvenes (48\%), sin embargo, son precisamente la personas más jóvenes quienes consideran menos atractiva a esta profesión, esta apreciación negativa disminuye gradualmente a medida que aumenta la edad de los encuestados. Esta tendencia presenta también variaciones respecto del nivel educativo, particularmente, en Bogotá, un alto porcentaje de ciudadanos con escolaridad básica consideran atractiva la profesión científica (53\%), mientras que esta apreciación disminuyó a medida que aumentó el nivel de estudios, llegando a representar el $31,9 \%$ de las respuestas de quienes tienen escolaridad superior (FECYT, OEI, et al., 2009, p. 108).

- En la Segunda Encuesta Nacional Argentina (Secretaría de Ciencia, Tecnología e Innovación Productiva, Observatorio Nacional de Ciencia, Tecnología e Innovación Productiva, 2007, p. 28-29), siete de cada diez argentinos piensan que los científicos tienen mucho o bastante prestigio. A medida que aumenta el nivel educativo de los encuestados, más favorable se torna esta opinión. Así como se considera prestigiosa la profesión de científico, también, en términos generales, se piensa que es "muy gratificante" en lo personal; seis de cada diez personas se inclinan por esta idea.

\section{SÍNTESIS CONCLUSIVA}

Las tecnociencias, contracción que señala la hibridación contemporánea entre ciencia y tecnología, tienden a incidir en forma exponencial en todas las dimensiones de la vida humana a nivel global, tanto como factor de desarrollo y bienestar como de incertidumbre y de riesgo. Éstas, en términos de su producción, distribución y consumo, responden a gran variedad de intereses de diversos actores estatales, privados y sociedad civil, lo que significa que la relación ciencia-tecnología-sociedad compromete tanto los sistemas tecnocientíficos, como los sistemas sociales en sus aspectos de tipo cultural, político y económico. Así, el diálogo público sobre la ciencia y la tecnología es un imperativo en las decisiones de política científica y una exigencia de la democracia; las tecnociencias deben ser valoradas, entre otros, en el contexto de los proyectos sociales e intereses a los que responden. En tal sentido, los estudios de percepción pública contribuyen a la identificación de escenarios tecnocientíficos y de políticas públicas al respecto, en tanto tienen potencial de aporte al desarrollo de la cultura científica, a la generación de desarrollos socialmente favorables y a la regulación del riesgo.

La percepción pública sobre la ciencia y la tecnología, en el marco de la cultura científica, implica un complejo conjunto de elementos que interactúan dinámicamente con la organización social y se expresan en contenidos cognitivos, simbólicos, institucionales, normativos y organizacionales relacionados con la producción y uso científico y tecnológico. En el presente estudio, así como aquellos efectuados en el marco del Proyecto Iberoamericano de Indicadores de Percepción Pública, Cultura Científica y Participación Ciudadana, se privilegian los componentes simbólicos expresados en actitudes y valoraciones, más que cognitivos o de alfabetización científica.

En el ámbito social de aplicación de las tecnociencias hacen presencia pluralidad de valores y agentes evaluadores, de manera que la experiencia vital de los 
sujetos y su particulares dinámicas sociales y culturales constituyen factores fundamentales para inclinar los conceptos hacia uno u otro lado de las escalas valorativas. De ahí la necesidad de situar allí las percepciones frente a la ciencia y la tecnología, de lo contrario, se enturbia una posible mirada comprensiva al respecto.

Los docentes y estudiantes de la Universidad de Caldas tienden a asociar la ciencia y la tecnología en función de su utilidad para el desarrollo social y el mejoramiento de la calidad de vida, predominantemente, las vinculan con el desarrollo de la humanidad. Sin embargo, en general se observa una actitud moderada en la que no se advierte demasiado optimismo, sino una actitud crítica que reconoce sus bondades en unos aspectos (salud y confort) y manifiesta claras reservas frente a otros (ambiente y erradicación de la pobreza y el hambre). Así mismo, las tecnociencias se perciben de difícil acceso al público y no correspondientes con las condiciones específicas del entorno (región-país). En suma, se trata, de una comunidad que en conjunto no se revela como protecnocientífica y mantiene una actitud reservada.

Al relacionar los indicadores de percepción con otras variables sociodemográficas, aunque no se presentan diferencias estadísticamente significativas, se advierte que: los docentes tienden a presentar actitud más esperanzadora frente a las tecnociencias que los estudiantes, aspecto que podría estar vinculado con el nivel socioeconómico y la escolaridad; las mujeres son algo más reservadas que los hombres; en las diferentes filiaciones religiosas, procedencia (rural - urbana) y campos del saber se presenta similitud; el autoposicionamiento político no presenta correspondencia con la opinión favorable hacia las tecnociencias; y aquellas personas que expresan conducta autónoma para el acceso a información sobre ciencia y tecnología tienden a mostrar mayor beneplácito hacia éstas.

La encuesta aplicada a una muestra representativa de docentes y estudiantes de la Universidad de Caldas, no sólo consultó los aspectos señalados en el presente artículo, que tienen que ver con valoraciones y significados, sino también con conductas relacionadas con la búsqueda autónoma de información sobre asuntos tecnocientíficos, lo cual arrojó una tendencia actitudinal. Teniendo en cuenta estos aspectos, se realizó una valoración del conjunto de las respuestas de cada una de las encuestas a partir de la cual los sujetos que respondieron fueron clasificados en una actitud optimista, moderada o pesimista. A manera de síntesis, la Tabla 3 da cuenta de la relación entre esta tendencia actitudinal y las distintas categorías de las variables sociodemográficas consultadas, lo cual ilustra lo arriba señalado.

ACTITUD ACERCA DE LA CIENCIA Y LA TECNOLOGÍA CON RESPECTO A LAS VARIABLES SOCIO-DEMOGRÁFICAS (\%)

\begin{tabular}{|l|l|l|l|l|}
\hline \multicolumn{2}{|c|}{} & OPTIMISTA & MODERADO & PESIMISTA \\
\hline \multirow{2}{*}{ GÉNERO } & Femenino & 5,2 & 66,2 & 28,6 \\
\cline { 2 - 5 } & Masculino & 4,6 & 71,4 & 23,9 \\
\hline \multirow{3}{*}{ PROCEDENCIA } & Rural & 3,7 & 66,7 & 29,6 \\
\cline { 2 - 5 } & Urbana & 3,6 & 66,3 & 30,1 \\
\hline \multirow{3}{*}{ ESTRATO } & Uno & 0,0 & 52,2 & 47,8 \\
\cline { 2 - 5 } & Dos & 3,0 & 57,6 & 39,4 \\
\cline { 2 - 5 } & Tres & 4,8 & 72,5 & 22,8 \\
\cline { 2 - 5 } & Cuatro & 8,4 & 67,5 & 24,1 \\
\hline
\end{tabular}




\begin{tabular}{|c|c|c|c|c|}
\hline & Cinco & 6,7 & 80,0 & 13,3 \\
\hline & Seis & 6,3 & 81,3 & 12,5 \\
\hline \multirow{3}{*}{ FILIACIÓN RELIGIOSA } & Católica & 5,7 & 71,2 & 23,1 \\
\hline & Ninguna & 3,7 & 67,2 & 29,1 \\
\hline & Otra & 3,1 & 68,8 & 28,1 \\
\hline \multirow{2}{*}{$\begin{array}{l}\text { PRACTICANTE } \\
\text { RELIGIOSO }\end{array}$} & No & 3,2 & 69,3 & 27,4 \\
\hline & $\mathrm{Si}$ & 6,8 & 74,6 & 18,6 \\
\hline \multirow{11}{*}{$\begin{array}{l}\text { AUTOPOSICIONAMIENTO } \\
\text { POLÍTICO (escala donde } \\
0 \text { es extrema derecha y } \\
10 \text { extrema izquierda) }\end{array}$} & 0 & 10,5 & 63,2 & 26,3 \\
\hline & 1 & 25,0 & 75,0 & 0,0 \\
\hline & 2 & 0,0 & 80,0 & 20,0 \\
\hline & 3 & 0,0 & 75,0 & 25,0 \\
\hline & 4 & 12,0 & 72,0 & 16,0 \\
\hline & 5 & 3,9 & 68,7 & 27,4 \\
\hline & 6 & 4,5 & 65,9 & 29,5 \\
\hline & 7 & 4,4 & 68,9 & 26,7 \\
\hline & 8 & 0,0 & 74,4 & 25,6 \\
\hline & 9 & 0,0 & 83,3 & 16,7 \\
\hline & 10 & 11,1 & 55,6 & 33,3 \\
\hline \multirow{2}{*}{ ESTAMENTO } & Estudiantes & 3,5 & 66,3 & 30,2 \\
\hline & Profesores & 10,5 & 78,9 & 10,5 \\
\hline \multirow{6}{*}{$\begin{array}{l}\text { ÁREA } \\
\text { CONOCIMIENTO }\end{array}$} & $\begin{array}{l}\text { Ciencias } \\
\text { Agropecuarias }\end{array}$ & 5,3 & 64,9 & 29,8 \\
\hline & $\begin{array}{ll}\text { Artes } & y \\
\text { Humanidades }\end{array}$ & 4,7 & 55,8 & 39,5 \\
\hline & $\begin{array}{ll}\text { Ciencias } & \\
\text { Exactas } \quad \text { y } \\
\text { Naturales }\end{array}$ & 1,6 & 70,5 & 27,9 \\
\hline & Ingenierías & 7,8 & 78,4 & 13,7 \\
\hline & $\begin{array}{ll}\text { Ciencias } & \\
\text { Jurídicas } & \text { y } \\
\text { Sociales } & \\
\end{array}$ & 4,1 & 70,7 & 25,2 \\
\hline & $\begin{array}{l}\text { Ciencias para } \\
\text { la Salud }\end{array}$ & 6,6 & 74,7 & 18,7 \\
\hline \multirow{2}{*}{$\begin{array}{lr}\text { COSTUMBRE } & \text { DE } \\
\text { BUSCAR INFORMACIÓN } \\
\text { CIENTÍFICA } \\
\text { TECNOLÓGICA } \\
\end{array}$} & No & 1,0 & 48,0 & 51,0 \\
\hline & $\mathrm{Si}$ & 6,0 & 74,8 & 19,2 \\
\hline
\end{tabular}

La imagen que se tiene de los científicos y la valoración que se realiza de esta profesión, tanto en docentes como estudiantes, exhibe un patrón de respuesta orientado hacia una mala valoración (poco reconocida, mal remunerada y poco atractiva), de ahí que la vocación se perciba como la principal motivación sobre otras incitaciones, tales como: el dinero, la búsqueda de la verdad, el prestigio, la solución de los problemas de la gente, el desarrollo del país y la filantropía. Concepto vinculable con idea de la baja calidad del mercado de trabajo de los científicos en el entorno, y la percepción sobre el poco desarrollo de la ciencia en la región (departamento de Caldas).

Al comparar estos resultados con los arrojados por las más recientes encuestas iberoamericanas disponibles, se encuentra similitud en buena parte de los 
resultados, las mayores diferencias se presentan en lo referido a la imagen de la profesión de investigador.

\section{BIBLIOGRAFÍA}

- Albornoz, M. (2003). Proyecto Iberoamericano de Indicadores de Percepción Pública, Cultura Científica y Participación Ciudadana. Revista Iberoamericana de Ciencia, Tecnología e Innovación CTS+l, No 5. http://www.oei.es/revistactsi/numero5/documentos1.htm

- Arroyo Menéndez, M. (2007). Tecnociencia y sociedad, 2006. Relación con la ciencia y la tecnología y percepciones ciudadanas, un análisis de datos secundarios. Madrid: Fundación Española para la Ciencia y la Tecnología (FECYT).

- Blanco, R. y J. M. Iranzo. (2000). Ambivalencia en incertidumbre en las relaciones entre ciencia y sociedad. Revista de Sociología, № 61 , pp. 89112.

- Centro de Estudios sobre Ciencia, Desarrollo y Educación Superior REDES-, Red Iberoamericana de Indicadores de Ciencia y Tecnología RICYT-, Observatorio Iberoamericano de la Ciencia, la Tecnología y la Sociedad -OCTS- (2009). El estado de la ciencia. Principales Indicadores de Ciencia y Tecnología Iberoamericanos / Interamericanos 2009. Buenos Aires.

- Colciencias. (2005). La Percepción que tienen los Colombianos sobre la Ciencia y la Tecnología. Bogotá: Colciencias.

- Cruces, J. M. y H. Vessuri. (2004). Ciencia y Tecnología. Venezolan@s participan y opinan. Caracas: Ministerio de Ciencia y Tecnología.

- Daza, S. (2008). Encuesta de percepción pública de la ciencia y la tecnología, Bogotá 2007. Bogotá: Observatorio Colombiano de Ciencia y Tecnología.

- Departamento Administrativo Nacional de Planeación (DANE). (2006). Censo General 2005, Nivel Nacional. Bogotá.

- Echeverría, J. (2003). La revolución tecnocientífica. Madrid: Fondo de Cultura Económica.

- Fundación Española de Ciencia y Tecnología (FECYT). (2003). Percepción Social de la Ciencia y la Tecnología en España - 2002. Madrid: Fundación Española Ciencia y Tecnología (FECYT).

- - (2005). Percepción Social de la Ciencia y la Tecnología en España - 2004. Madrid: Fundación Española Ciencia y Tecnología (FECYT).

- (2007). Percepción Social de la Ciencia y la Tecnología en España - 2006. Madrid: Fundación Española Ciencia y Tecnología (FECYT).

- (2009). Percepción Social de la Ciencia y la Tecnología en España - 2008. Madrid: Fundación Española para la Ciencia y la Tecnología (FECYT).

- Fundación Española de Ciencia y Tecnología (FECYT), Organización de Estados Americanos (OEI), et al. (2009). Cultura científica en Iberoamérica. Encuesta en grandes núcleos urbanos. FECYT, OEI, RICYT.

- láñez Pareja, E. y Sánchez Cazorla, J. A. "Una aproximación a los estudios de Ciencia, Tecnología y Sociedad (CTS)". En http://www.ugr.es/ eianez/Biotecnologia/cts.htm, obtenido 4 de abril de 2008. 
- Lafuente, A. y T. Saraiva. (2002). Los públicos de la ciencia. Madrid: Fundación Española para la Ciencia y la Tecnología y Ministerio de Ciencia y Tecnología.

- Moreno, L. y J. L. Lujan. (1996). El cambio tecnológico en las ciencias sociales: el estado de la cuestión. Revista española de investigaciones sociológicas $\quad \mathrm{N}^{\circ} \quad 74, \quad \mathrm{pp} . \quad 127-\quad 162$. Observatorio Colombiano de Ciencia y Tecnología. (2009a). Indicadores de ciencia y tecnología, Colombia 2008. Colombia.

- (2009b). Indicadores de ciencia y tecnología, Colombia 2009.

\section{Colombia.}

- Organización de Estados Iberoamericanos (OEI) y Red Iberoamericana de Ciencia y Tecnología (RICYT). (2003). Proyecto Iberoamericano de Indicadores de Percepción Pública, Cultura Científica y Participación Ciudadana. Revista Iberoamericana de Ciencia, Tecnología e Innovación, 5,60 .

- Peña, J. M. (2005). La percepción pública de la ciencia en México. Revista Ciencias. Universidad Nacional Autónoma de México.

- Polino, C., Fazio, M.E. y Vacarezza, L. (2003). Medir la percepción pública de la ciencia en los países iberoamericanos. Aproximación a problemas conceptuales. Revista Iberoamericana de Ciencia, Tecnología, Sociedad e Innovación CTS+I, número 5.

- Polino, C., L. Vaccarezza y Fazio, M. E. (2004). Indicadores de percepción pública de la ciencia. Aplicación de la experiencia RICYT/OEI en la encuesta nacional de Argentina y comparación internacional. Estado de la ciencia 2003. Buenos Aires: Red Iberoamericana de Ciencia y Tecnología (RICYT).

- Quintanilla, M. Á. (2001). Técnica y cultura. En López Cerezo, J. A., Lujan J. L. y García Palacio, E. M. (Eds.), Filosofía de la tecnología (pp. 55-76). Madrid: Organización de los Estados Iberoamericanos para la Educación, la Ciencia y la Cultura.

- Ramírez R., G. (2004). Los sistemas nacionales de ciencia y tecnología en Iberoamérica. Oviedo: Universidad de Oviedo.

- Secretaría de Ciencia, Tecnología e Innovación Productiva (SeCyT) y Ministerio de Educación, Ciencia y Tecnología. (2004). Los argentinos y su visión de la ciencia y la tecnología (primera encuesta nacional de percepción pública de la ciencia). Buenos Aires: Secretaría de Ciencia, Tecnología e Innovación Productiva. Ministerio de Educación, Ciencia y Tecnología (SeCyT). Ministerio de Educación, Ciencia y Tecnología.

- Secretaría de Ciencia, Tecnología e Innovación Productiva, Observatorio Nacional de Ciencia, Tecnología e Innovación Productiva (2007). La percepción de los argentinos sobre la investigación científica en el país. Segunda encuesta nacional. Buenos Aires.

- Torres, C. (2005). Representaciones sociales de la ciencia y la tecnología. Revista española de investigaciones sociológicas, № 111, pp. 9-44.

- Vaccarezza, L., J. A. López Cerezo, Lujan, J. L., Polino, C., Fazio, M.E. (2003). Proyecto iberoamericano de indicadores de percepción pública, cultura científica y participación ciudadana (RICYT/CYTED-OEI). Documento de trabajo No. 7. Argentina: REDES (Centro de Estudios sobre Ciencia y Educación Superior).

- Winner, L. (2001). Dos visiones de la civilización tecnológica. En J. A. López y J. M. Sánchez (Eds.), Ciencia, tecnología, sociedad y cultura en el cambio de siglo (pp. 55-68). Madrid: Editorial Biblioteca Nueva, Organización de Estados Iberoamericanos. 
1. Docente Titular Universidad de Caldas. Trabajadora Social, Magíster en Desarrollo Educativo y Social, Especialista en Estudios Sociales de la Ciencia y la Innovación Tecnológica.

2. "Hasta la segunda guerra mundial se hablaba del progreso de las naciones. Con la post guerra la economía adopta el vocablo 'desarrollo' para designar ese proceso que cada vez se fue haciendo más complejo porque cada quien le sumaba ingredientes: creciente - autosostenido - de producción de bienes y servicios. Se inició como desarrollo económico y pronto añadió lo social: acompañado por una distribución - equitativa - de la riqueza - y de los servicios sociales. Alguien dijo que el orden estaba invertido y pasó a ser socio-económico. Entonces, aparecieron las especialidades. El desarrollo político, administrativo, educativo, cultural, científico-tecnológico, ambiental y sustentable. Hace pocos años Naciones Unidas cayó en cuenta de que el desarrollo es la sumatoria de todas estas especialidades [...] lo llamó desarrollo integral. Más recientemente, la Organización ha acuñado el concepto de desarrollo humano, pero esta vez sin pretensiones de integralidad sino como la resultante de un conjunto de indicadores de la realidad de los países. En verdad el desarrollo de un país es uno solo porque una sola es la realidad donde se produce o se le busca. Cada apellido sólo indica que quien lo usa desea enfocar ese desarrollo desde una óptica específica. Así, el desarrollo científico y tecnológico nacional es el desarrollo de un país mirado desde el punto de vista de cuánto y cómo pueden contribuir la Ciencia y la Tecnología a su logro" (Ramírez, 2004).

3. "En el caso de las empresas tecnocientíficas, los financieros, los empresarios, los gestores, los juristas, los científicos y los ingenieros forman parte del núcleo de la tecnociencia, auque también hay que contar con apoyos políticos e institucionales, llegado el caso, y con una buena recepción social [...] En la periferia de la tecnociencia están los grupos ecologistas, los medios de comunicación, las fundaciones y las empresas de intermediación" (Echeverría, 2003, p. 219).

4. El Modo 2 de producción de conocimiento, "se lleva a cabo en el contexto de aplicación, y se caracteriza por su transdisciplinaridad, heterogeneidad, heterarquía y transitoriedad organizativa, responsabilidad social y reflexividad, y control de calidad que resalta la dependencia del contexto y del uso" (Blanco \& Iranzo, 2000, p. 98).

5. Este proyecto ha contado además con el apoyo de: la Agencia Española de Cooperación Internacional para el Desarrollo (AECID, España); la Fundação de Amparo à Pesquisa do Estado de São Paulo (FAPESP, Brasil); la Comisión Nacional de Investigaciones Científicas y Tecnológicas (CONICYT, Chile); Colciencias y el Observatorio de Ciencia y Tecnología (Colombia); la Secretaría de Ciencia y Tecnología (SENACYT, Panamá); el Ministerio de Ciencia y Tecnología (MCT, Venezuela); el Centro de Investigaciones Energéticas, Medioambientales y Tecnológicas (CIEMAT, España); el Consejo Superior de Investigaciones Científicas (CSIC, España); además de otros organismos e instituciones públicas de ciencia y tecnología y enseñanza de la región iberoamericana.

6. "El informe de la National Science Foundation (NSF, 2004), comparado con los resultados de Estados Unidos y la Unión Europea (Eurobarómetro, 2001), indica que la mayoría de los norteamericanos (86\%) y de los europeos $(71 \%)$ piensa que "la ciencia y la tecnología están haciendo nuestras vidas más saludables, fáciles y confortables" [...] La encuesta española realizada por FECYT (2003) muestra gran confianza (84\%) de la población en el accionar de la ciencia y la tecnología para resolver cuestiones vinculadas con la salud [...] También para el público de Nueva Zelanda (Ministry of Research, Science and Technology, 2002), la ciencia y la tecnología son muy benéficas particularmente debido al desarrollo de 
nuevas técnicas y tratamientos médicos (68\%); ante la idea de que la ciencia y la tecnología mejoran los estándares y las comodidades de vida de la población, así como una mayoritaria esperanza en el progreso de la ciencia "ayudará a encontrar la cura para enfermedades cono el Sida y el Cáncer" (89\%); variable que también registra una muy alta adhesión $(92,7 \% 9$ para el caso argentino en la encuesta RICYT/OEI, y europeo $(80,5 \%)$, según datos del Eurobarómetro (2001). Según la encuesta de SENAYT (2001) sobre la población de Panamá, para el público, la ciencia y la tecnología contribuyen a resolver problemas de salud $(69,3)$ y, por lo tanto, a mejorar la vida de las personas (54\%). También la encuesta de Colombia (Colciencias, 1994) exhibe resultados similares" (Polino, Vaccarezza y Fazio, 2004, p. 5).

7. Se realizó una prueba $t$ de muestras independientes con varianzas iguales, obteniendo que no existe diferencia entre la respuesta media de ambos estamentos (Pvalor $=0,245$ ).

8. Se realizó un análisis de varianza a una vía por bloques, donde el factor fue la variable estrato con seis niveles. Los bloques fueron las diferentes preguntas realizadas ( 8 en total). No se encontró diferencia significativa entre los estratos (o sea que los valores promedio dados a las preguntas fueron estadísticamente iguales). El Pvalor obtenido fue de 0,6356.

9. El Pvalor obtenido fue de 0,3164. Se encontró diferencia entre bloques (Pvalor $=0$ ), o sea que los valores promedio dados a las diferentes preguntas fueron distintos (lo cual es lógico, ya que las preguntas eran diferentes). Las medias totales para autoposicionamiento religioso entre católica, otra y ninguna, son iguales estadísticamente (análisis de varianza a una vía por bloques, donde el factor fue la variable autoposicionamiento religioso, el cual posee tres niveles: católico, otro y ninguno, y los bloques fueron las diferentes preguntas realizadas -8 en total-).

10. El autoposicionamiento político fue identificado mediante ubicación en una escala en la que cero corresponde a extrema derecha y diez corresponde a la extrema izquierda.

11. Tipos de valores de las tecnociencias: básicos, epistémicos, tecnológicos, económicos, militares, políticos, jurídicos, sociales, ecológicos, religiosos, estéticos, morales. (Echeverría, 2003). 